\title{
Application of Simulated Annealing Algorithm to Wireless Sensor Networks
}

by

Jiye Liao

A thesis submitted to the Faculty of Graduate Studies and Research

in partial fulfilment of the requirements for the degree of

Master of ENCWNERTING in Technology Innovation Management

\author{
Department of Systems and Computer Engineering \\ Carleton University \\ Ottawa, Canada, K1S 5B6 \\ Jun, 2006
}

(C) Copyright 2006 Jiye Liao 


$\begin{array}{ll}\begin{array}{l}\text { Library and } \\ \text { Archives Canada }\end{array} & \begin{array}{l}\text { Bibliothèque et } \\ \text { Archives Canada }\end{array} \\ \begin{array}{l}\text { Published Heritage } \\ \text { Branch }\end{array} & \begin{array}{l}\text { Direction du } \\ \text { Patrimoine de l'édition }\end{array} \\ \begin{array}{l}\text { 395 Wellington Street } \\ \text { Ottawa ON K1A 0N4 } \\ \text { Canada }\end{array} & \begin{array}{l}\text { 395, rue Wellington } \\ \text { Ottawa ON K1A ON4 } \\ \text { Canada }\end{array}\end{array}$

Your file Votre référence ISBN: 978-0-494-18357-1 Our file Notre référence ISBN: 978-0-494-18357-1

NOTICE:

The author has granted a nonexclusive license allowing Library and Archives Canada to reproduce, publish, archive, preserve, conserve, communicate to the public by telecommunication or on the Internet, loan, distribute and sell theses worldwide, for commercial or noncommercial purposes, in microform, paper, electronic and/or any other formats.

The author retains copyright ownership and moral rights in this thesis. Neither the thesis nor substantial extracts from it may be printed or otherwise reproduced without the author's permission.
AVIS:

L'auteur a accordé une licence non exclusive permettant à la Bibliothèque et Archives Canada de reproduire, publier, archiver, sauvegarder, conserver, transmettre au public par télécommunication ou par l'Internet, prêter, distribuer et vendre des thèses partout dans le monde, à des fins commerciales ou autres, sur support microforme, papier, électronique et/ou autres formats.

L'auteur conserve la propriété du droit d'auteur et des droits moraux qui protège cette thèse. $\mathrm{Ni}$ la thèse ni des extraits substantiels de celle-ci ne doivent être imprimés ou autrement reproduits sans son autorisation.
In compliance with the Canadian

Privacy Act some supporting forms may have been removed from this thesis.

While these forms may be included in the document page count, their removal does not represent any loss of content from the thesis.
Conformément à la loi canadienne sur la protection de la vie privée, quelques formulaires secondaires ont été enlevés de cette thèse.

Bien que ces formulaires aient inclus dans la pagination, il n'y aura aucun contenu manquant.

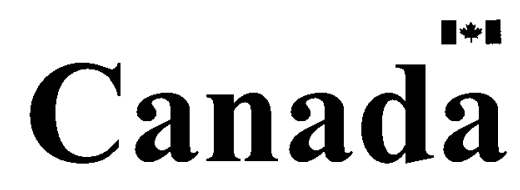




\begin{abstract}
This thesis introduces a new protocol called the simulated annealing (SA) chain algorithm for data gathering and communication in wireless sensor networks. The SA algorithm was applied in the base station to form an approximately optimal chain. The results of simulations on data gathering and communication in a wireless sensor network show that the SA chain algorithm performs much better than the direct transmission protocol and the PEGASIS (power-efficient gathering in sensor information system) protocol, in terms of network structure, energy efficiency, and lifetime.
\end{abstract}




\section{ACKNOWLEDGEMENTS}

I am truly grateful to all the people who helped and supported me in the completion of this thesis. This work would not have been done without them.

I would like to express my gratitude to my supervisor, Professor Xiaoping Liu, for his guidance, understanding and patience in the development of this thesis. I appreciate the manner and style with which he supervised this study.

I also thank Professor John Callahan for his comments and help.

Finally, I dedicate this thesis to my parents, Mr. Liao Sicheng and Mrs. Wang Huiqun. Their love and support is extremely valuable to me. 
1 INTRODUCTION................................................................................................ 1

$1.1 \quad$ Background of wireless sensor networks ................................................................................. 1

1.2 Challenges................................................................................................... 1

1.3 The SA chain protocol ................................................................................................................. 2

1.4 Contribution .................................................................................................................................... 2

1.5 Thesis structure ...................................................................................................................

2 WIRELESS SENSOR NETWORK …..............................................................

$2.1 \quad$ Introduction.....................................................................................................................................

2.2 WSN architecture ..............................................................................................................

2.3 WSN sensor node architecture...................................................................................................... 8

2.4 Characteristics of WSN .............................................................................................................

2.4.1 Limitations concerning communication capability.............................................................. 10

2.4.2 Limitations concerning energy ............................................................................................ 10

2.4.3 Limitations concerning computation capability ................................................................. 11

2.4.4 Large quantity of nodes................................................................................................................. 11

2.4.5 Dynamic network................................................................................................................ 11

2.5 Performance evaluation of WSNs.................................................................................. 12

2.5.1 Energy efficiency ..................................................................................................................... 12

2.5.2 Lifetime................................................................................................................................ 12

2.5.3 Time delay ............................................................................................................ 12

2.5.4 Sensing accuracy .............................................................................................................. 13

2.5.5 Fault tolerance ............................................................................................................................. 13

3 WSN PROTOCOLS ......................................................................................................... 14

3.1 WSN MAC protocols .............................................................................................................. 14

3.1.1 Scheduled protocols ...................................................................................................................... 15

3.1.1.1 TDMA ……............................................................................................................. 15

3.1.1.2 FDMA....................................................................................................................... 16

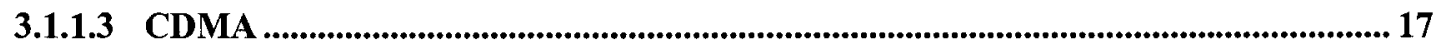

3.1.1.4 TDM-FDM...................................................................................................... 18

3.1.1.5 SMACS ........................................................................................................... 18

3.1.1.6 DE-MAC …....................................................................................................... 18 


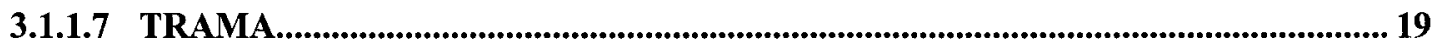

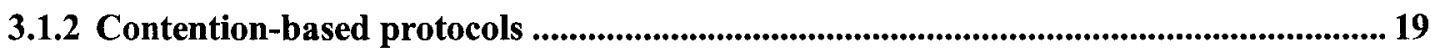

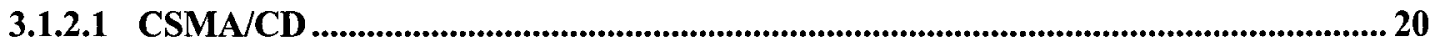

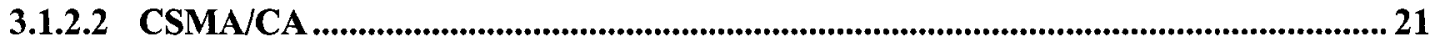

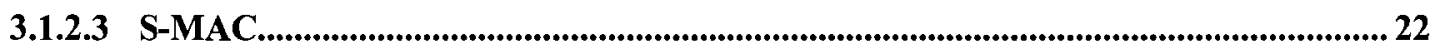

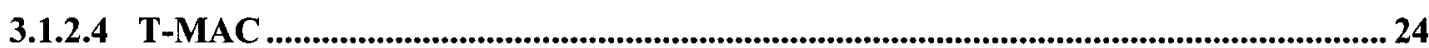

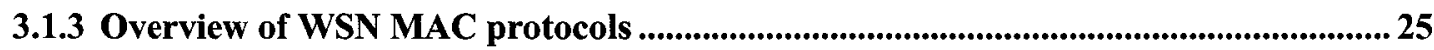

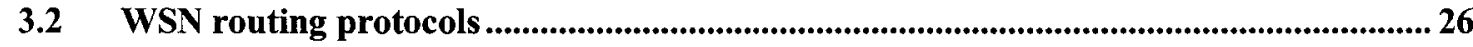

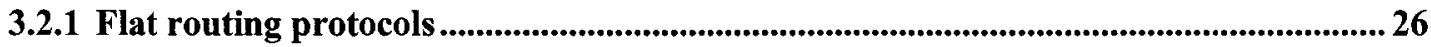

3.2.2 Direct transmission .................................................................................................................... 27

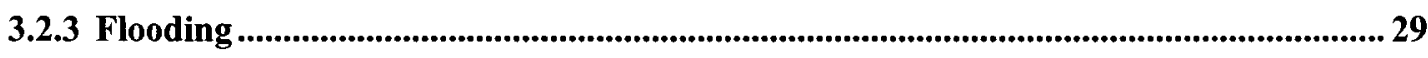

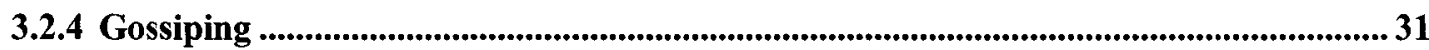

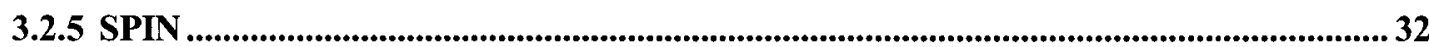

3.2.6 Hierarchical routing protocols …............................................................................................ 32

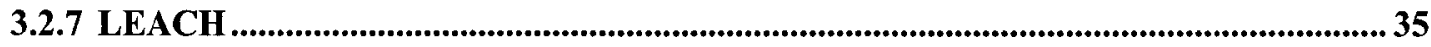

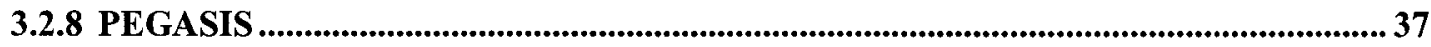

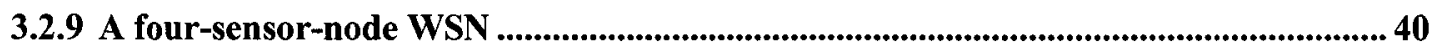

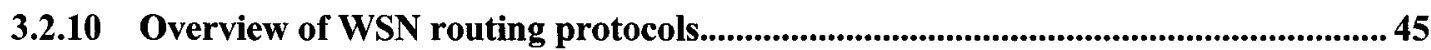

4 TRAVELING SALESMAN PROBLEM AND SIMULATED ANNEALING

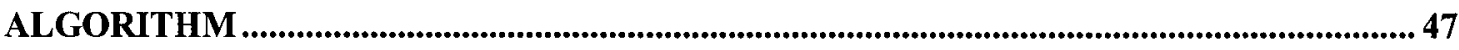

4.1 Traveling salesman problem ..................................................................................................... 48

4.1.1 Definition of traveling salesman problem...................................................................48

4.1.2 Definition of a Hamiltonian cycle...................................................................................... 48

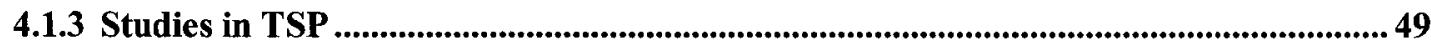

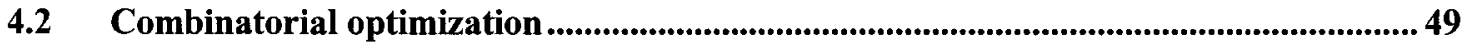

4.2.1 Definition of combinatorial optimization................................................................................50

4.2.2 Algorithms and their computational complexity ……............................................................51

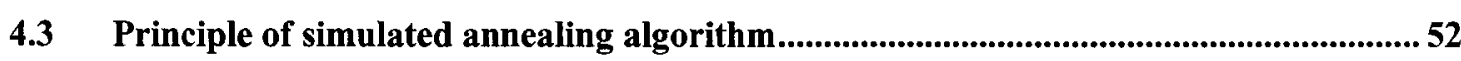

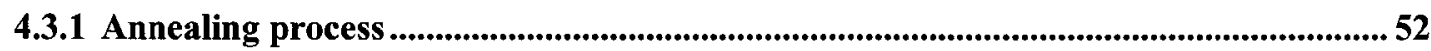

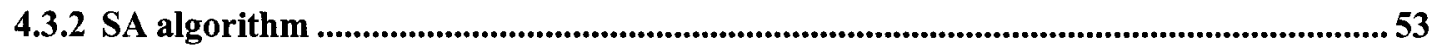

4.3.3 Flow chart of SA algorithm .......................................................................................................... 53

4.4 An example of SA algorithm in solving the TSP .................................................................57

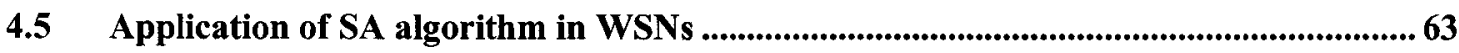

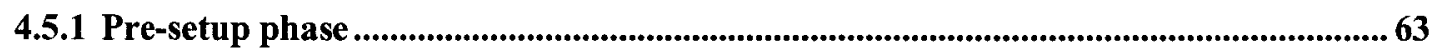


4.5.2 Chain set-up phase..................................................................................................................64 64

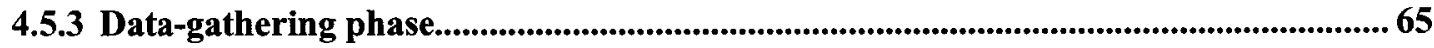

4.5.4 Reconfiguration phase .............................................................................................................6 66

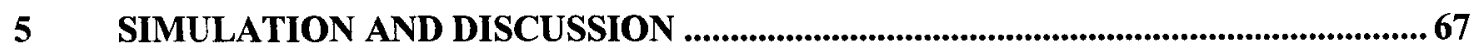

5.1 Simulation environment and assumptions.......................................................................68

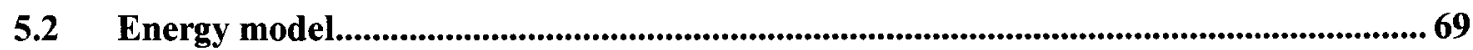

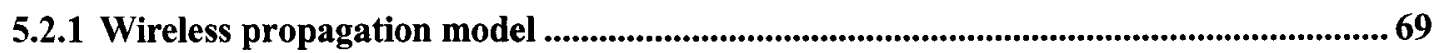

5.2.2 Energy consumption model ..................................................................................................... 70

5.3 Small-scale WSN with 10 sensor nodes .................................................................................... 72

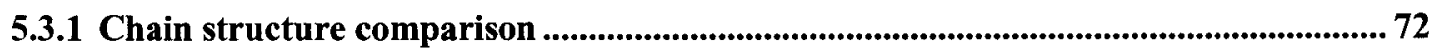

5.3.2 Energy efficiency and computation time comparison .............................................. 74

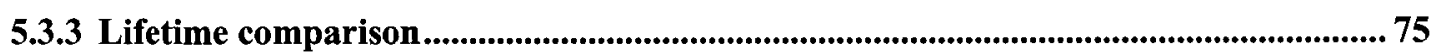

5.4 Medium-scale WSN with 100 sensor nodes ................................................................... 76

5.4.1 Chain structure comparison ................................................................................................... 76

5.4.2 Energy efficiency comparison........................................................................................................ 78

5.4.3 Lifetime comparison ..................................................................................................................... 79

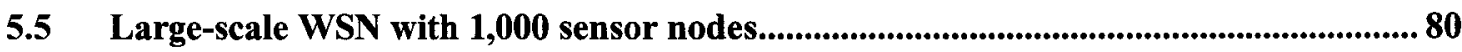

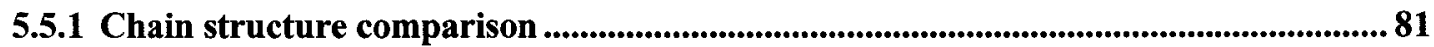

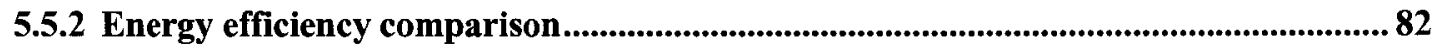

5.5.3 Lifetime comparison ........................................................................................................................ 84

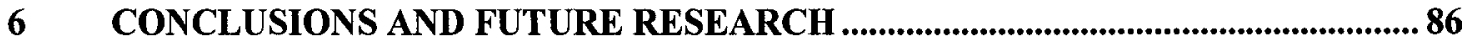

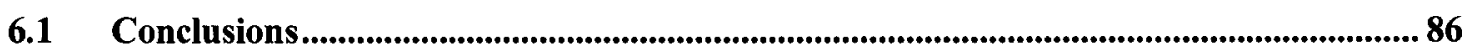

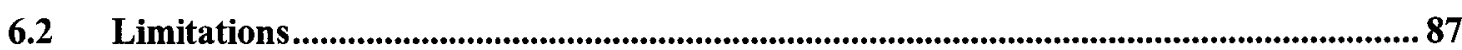

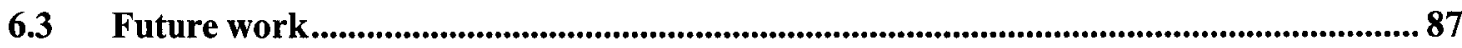

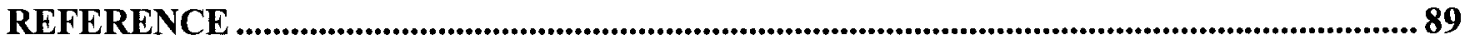




\section{LIST OF FIGURES}

Figure 1: A typical WSN network architecture...............................................................................6 6

Figure 2: Another type of WSN network architecture ......................................................................... 7

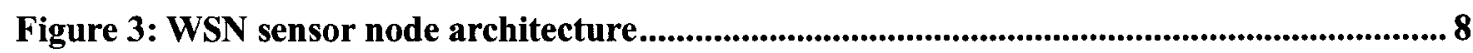

Figure 4: A WSN node......................................................................................................................... 9

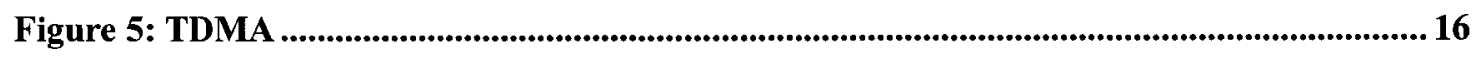

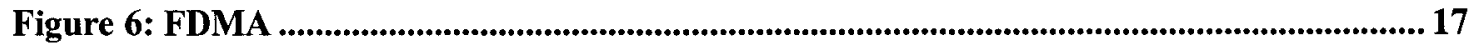

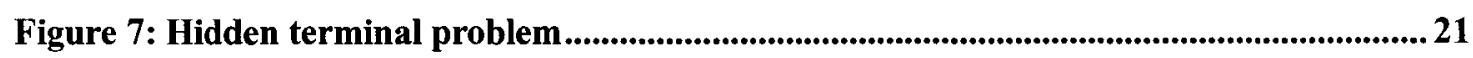

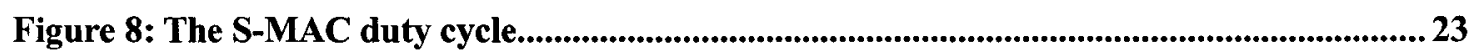

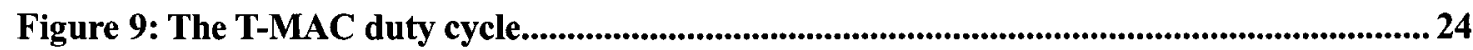

Figure 10: Flat routing protocols .................................................................................................. 27

Figure 11: Direct transmission .................................................................................................................. 28

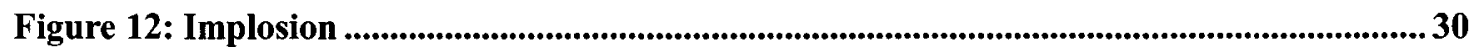

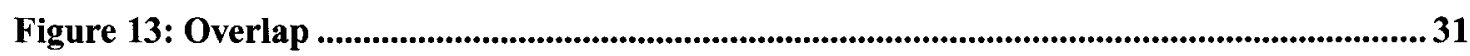

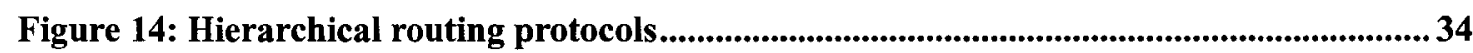

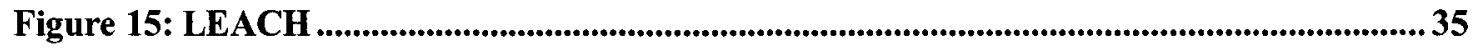

Figure 16: PEGASIS ...................................................................................................................................... 38

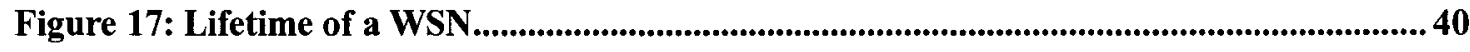

Figure 18: Direct transmission in a four-sensor-node WSN ........................................................ 41

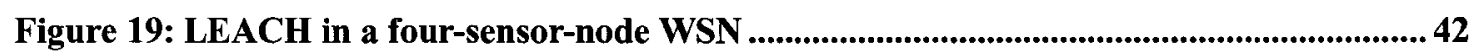

Figure 20: PEGASIS in a four-sensor-node WSN ..................................................................... 43

Figure 21: Flow chart of SA algorithm.....................................................................................56

Figure 22: 100 cities in a $1,000 \mathrm{~km} 2$ area.................................................................................................58

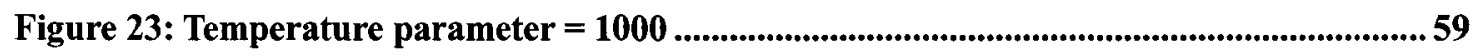

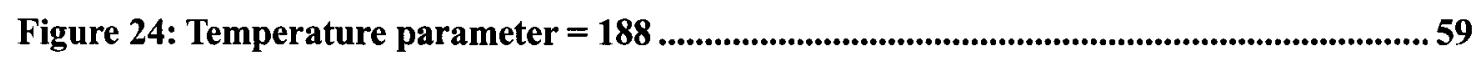

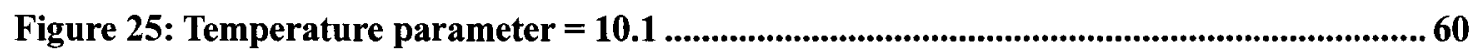

Figure 26: Temperature parameter $=0.001$...................................................................................60

Figure 27: Total length and computation time..............................................................................62

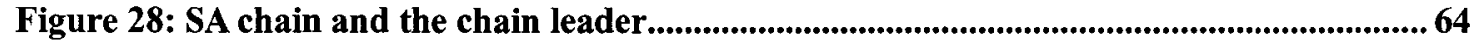

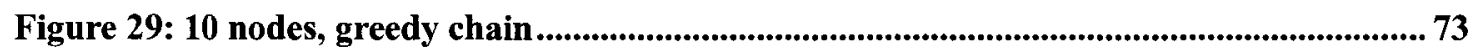

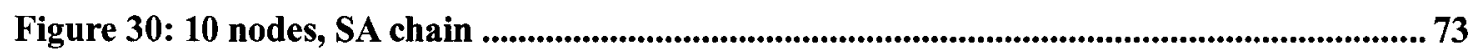

Figure 31: Energy efficiency and computation time comparison in a 10-node WSN................ 75 


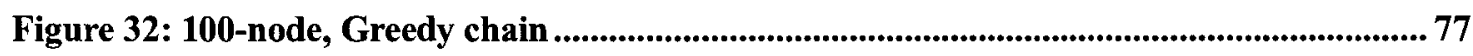

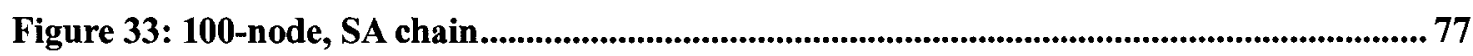

Figure 34: Energy efficiency and computation time comparison in a 100-node WSN............. 79

Figure 35: 1,000-node, Greedy chain .............................................................................................. 81

Figure 36: 1,000-node, SA chain.......................................................................................................8 82

Figure 37: Energy efficiency and computation time comparison in a 1,000-node WSN........... 84 


\section{LIST OF TABLES}

Table 1: Comparison of direct transmission, LEACH and PEGASIS protocols........................ 46

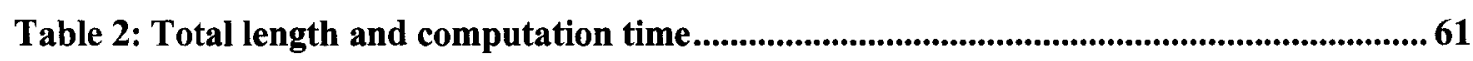

Table 3: Energy efficiency and computation time comparison in a 10-node WSN .................. 74

Table 4: Lifetime comparison in a 10-node WSN.......................................................................... 76

Table 5: Energy efficiency and computation time comparison in a 100-node WSN ................ 78

Table 6: Lifetime comparison in a 100-node WSN..................................................................... 80

Table 7: Energy efficiency and computation time comparison in a 1,000-node WSN ..............83

Table 8: Lifetime comparison in a 1,000-node WSN................................................................85 


\section{INTRODUCTION}

This chapter will introduce the background of a wireless sensor network (WSN) and its applications. The challenges and difficulties of implementing a WSN will be reviewed, and the solution we have developed, the simulated annealing (SA) chain protocol, introduced briefly. Finally, the contributions of this thesis will be identified.

\subsection{Background of wireless sensor networks}

The wireless sensor network (WSN) is a new communication technology. The first WSN was "smart dust," which was developed in USA Department of Defence (DOD)-funded research at the University of California, Berkeley in the late 1990 s. The objective of this research is to develop a new network that features cheap, low power and tiny sensor nodes, which can monitor temperature, light, or vibrations-or even sniff out radiation or toxic chemicals.

WSN has been applied in many areas, and examples can be found in [1-7]. It also has civic $[8,9,10$, and 15$]$ applications and military applications [2 and 3].

\subsection{Challenges}

There are many challenges in implementing a WSN, ranging from hardware to software to mechanical challenges. Keeping the power consumption sufficiently low so that the 
WSN is able to operate for a long period of time involves careful development of data gathering and routing protocols. The radio communication hardware usually has to be small enough, while using a suitable network algorithm.

\subsection{The SA chain protocol}

In this thesis, we introduce a data-gathering and communication algorithm called the SA chain protocol for WSN. It provides energy-efficient and low-cost communication compared to some other protocols, such as the famous PEGASIS (power-efficiency gathering in sensor information system) protocol.

\subsection{Contribution}

The main contributions of this thesis are:

- Development of a new data gathering and communication protocol, the SA chain protocol, based on a highly recognized optimization method, the simulated annealing algorithm. The SA chain protocol is run at the base station and quickly creates a globally approximated optimal chain for data communication. The communication route formed by the simulated annealing algorithm optimizes the total energy cost of the network. This is very important, since energy efficiency is the main constraint that remains for WSN. 
- Comparison of three different WSN data communication protocols: the direct transmission, PEGASIS and SA chain protocols. The simulation results show that the SA chain protocol can provide high network performance results in terms of energy efficiency, lower cost, reliability, and data quality.

\subsection{Thesis structure}

The structure and characteristics of wireless sensor networks are introduced in Chapter 2. The performance evaluations for WSN will then be described, with emphasis on WSN energy efficiency and lifetime.

Chapter 3 provides a survey of the most adopted media access control (MAC) protocols and routing protocols. We focus on the routing protocols and compare three famous routing protocols in different WSNs.

Chapter 4 introduces the traveling salesman problem (TSP), which is similar to WSN communication and routing. We introduce the simulated annealing algorithm, which can approximately solve TSP in a short period of time. We develop a SA chain protocol for WSN data gathering and communication. 
In Chapter 5, the SA chain protocol is simulated in different situations. The SA chain protocol is compared with two other well-known protocols, and the simulation results show that the SA chain protocol performs best.

Chapter 6 summarizes the advantages of the SA chain protocol and indicates new topics for research. 


\section{WIRELESS SENSOR NETWORK}

This chapter introduces the structure and characteristics of a WSN. The performance evaluations for WSNs will be described, with an emphasis on energy efficiency and lifetime for a WSN.

\subsection{Introduction}

A wireless sensor network (WSN) is an infrastructure-less and self-organized network. It is composed of a group of sensor nodes, which communicate by electromagnetic waves. Each sensor node acts as both a sensor and a wireless router. The fundamental functions of WSNs are sensing, data gathering, processing information on monitored objects and transferring the information to the base station.

\subsection{WSN architecture}

There are three basic components in a WSN: user (base station), sensors and the objects to be monitored. Electromagnetic waves are the communication carriers between sensors and users. The communication protocol is ad hoc. For an ad hoc network, each node serves as a router, the functions of which include route searching, data storing and forwarding. 
The users of WSN are the information receivers, which can be human or a piece of equipment. For instance, an army commander can be a user of a WSN, and the black box of a fighter jet can also be a user of a WSN. A WSN can have multiple users.

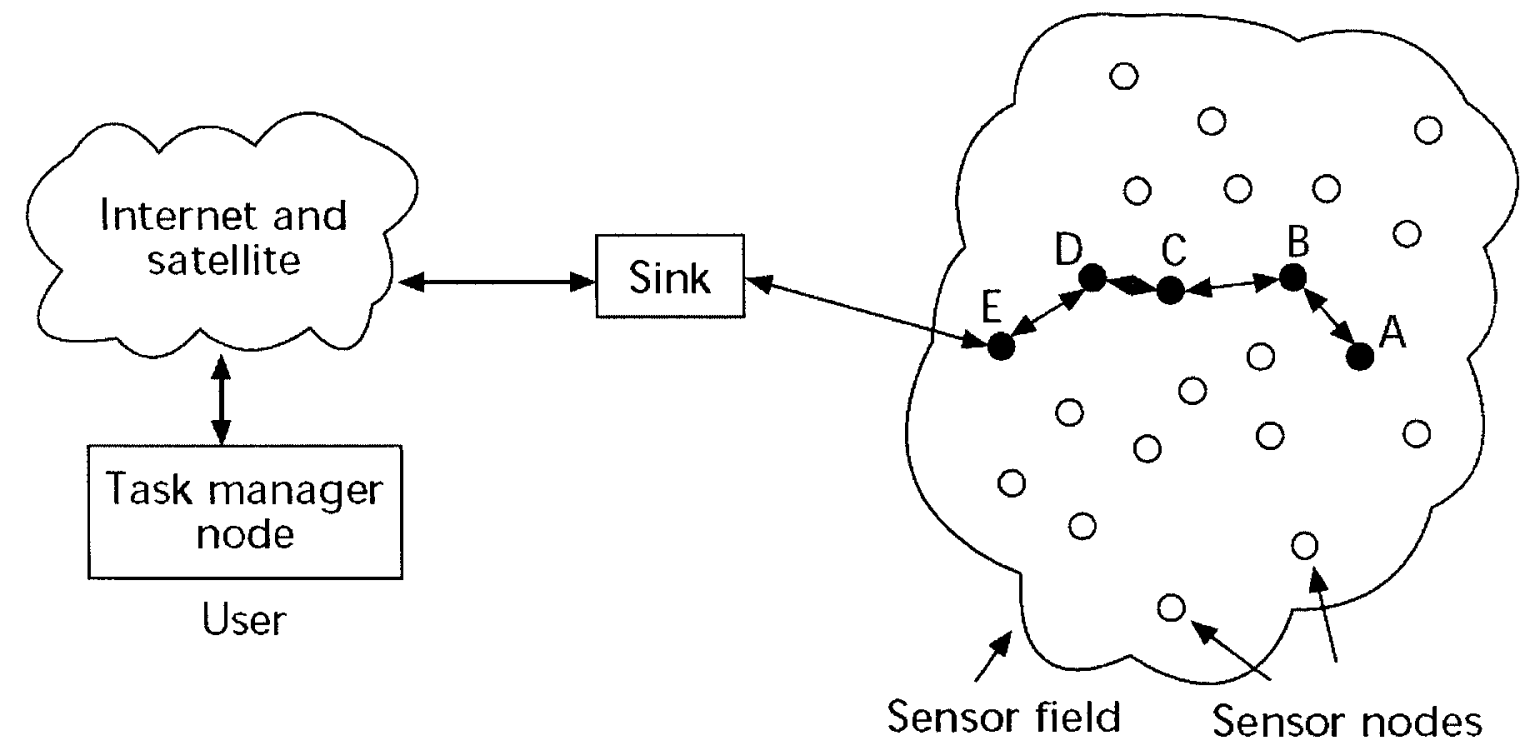

Figure 1: A typical WSN network architecture

Figure 1 shows a typical WSN network architecture [11]. This network consists of sensor nodes, sink (base station), internet/satellite, and task manager node/users. The sensor nodes are deployed in the appointed field, the sensor field. Each node can sense data from objects in the sensor field, and send the sensed data to the base station via an assigned route. In the same way, the base station can send information to each node. The base station/sink connects with the task manager node/user through the internet or satellites. In 
some applications, sensor nodes are deployed in fixed locations, but in other applications, they may be mobile [11].

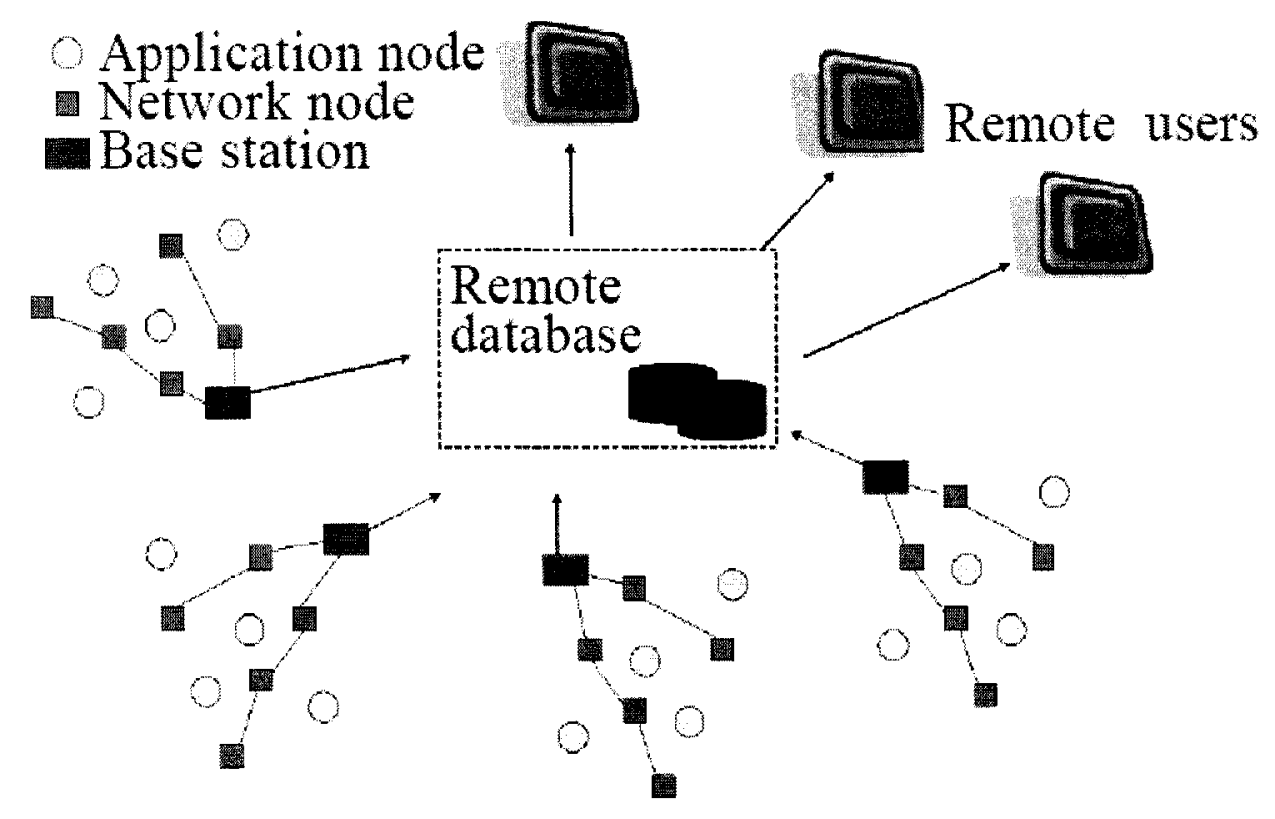

Figure 2: Another type of WSN network architecture

Figure 2 shows another type of WSN network architecture [11]. In this architecture, the base station forwards information from a few WSNs to a remote database. The sensor nodes can be fixed nodes or application nodes. Application nodes are mobile nodes. The fixed nodes send information to the base station via wired lines. The application nodes send information to the base station or the fixed nodes by electromagnetic waves. 


\subsection{WSN sensor node architecture}

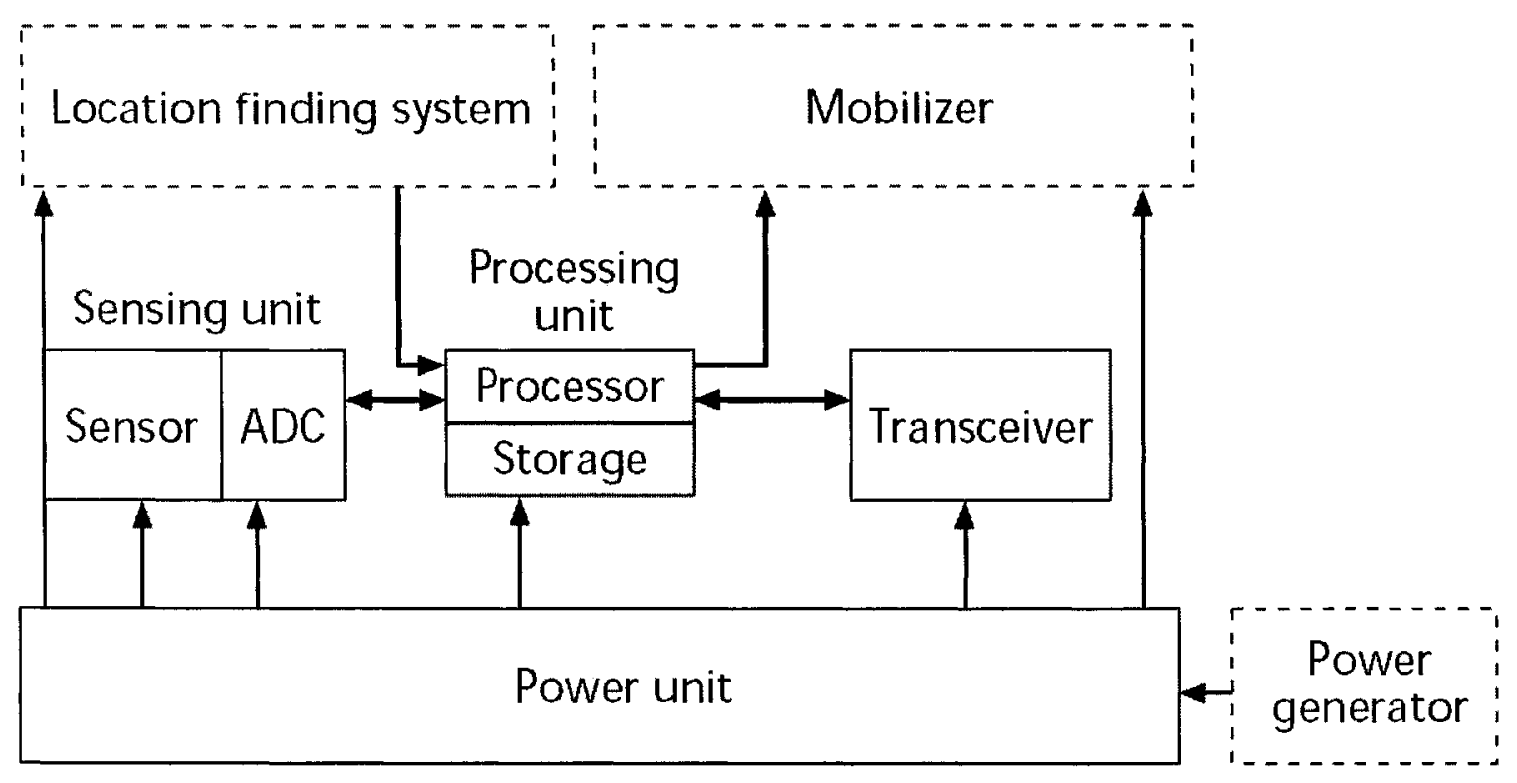

Figure 3: WSN sensor node architecture

Figure 3 shows the WSN node architecture [11]. The solid-line boxes represent the basic modules of WSN. The dashed-line boxes represent the additional modules. The basic modules include a sensor, an analog/digital converter (ADC), a processor, storage, a transceiver, and a power unit. The sensor detects information from the targets. It usually outputs an analog signal. The ADC converts the analog signal into digital data. The processor controls the whole sensor node and processes the digital data from the ADC. The transceivers modulate/demodulate the data into an electromagnetic wave and transmit/receive the electromagnetic wave to/from other nodes or base stations. The power unit is usually a battery. 
The additional modules include a location-finding system, a mobilizer, and a power generator. The location-finding system can be a global positioning system (GPS) or other type of localizer system. The mobilizer can be a vehicle, aircraft, or other mobile equipment.

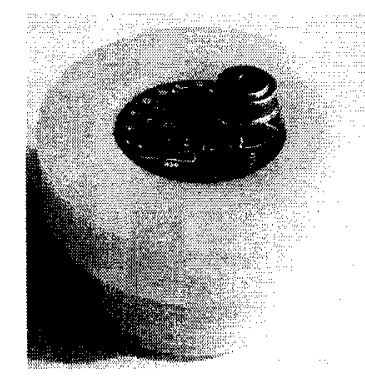

\section{Figure 4: A WSN node}

Figure 4 shows a WSN node. Because they are small, WSN sensor nodes can be deployed in many harsh environments, such as volcanoes, or even inside human bodies. In the near future, the price of each sensor node will be only 5 to 10 US dollars. At this price, adopting WSNs will be easy.

\subsection{Characteristics of WSN}

A WSN has characteristics in common with an ad hoc network, such as mobility and discontinuity. Furthermore, because the size is small and the sensor nodes cannot be too expensive, a WSN has some special characteristics. 


\subsubsection{Limitations concerning communication capability}

Communication bandwidth and quality vary greatly. When obstructed by mountains and buildings, the sensor nodes tend to disconnect from the network and work offline for a long time. How to transmit and receive information under limited communication conditions is one of the hottest research topics in WSN.

\subsubsection{Limitations concerning energy}

In most WSNs, a sensor node's sole energy resource is a battery. In military applications, once a WSN has been deployed, the sensor nodes cannot be replaced or recharged, although they can be in some civil applications. However, the cost of replacing or recharging may be greater than the value of the sensor node.

Therefore, powering the sensor node is usually a large constraint. Figure 2.3-1 shows that all the modules consume battery power. The sensor module, the ADC, and the processor only consume a small amount of energy. The main power consumer is the transceiver. In some situations, the energy needed to transmit only 1 bit of information can execute 5,000 commands in the processor module.

Once a sensor node has used up all the energy, the WSN network as a whole loses that part of the network and the sensor field is reduced. This phenomenon is the so-called "death of the node". Usually, a WSN sensor node can survive from a couple of hours to a 
few months. How to use energy effectively and maximize the lifetime of the network is the most important problem in research and WSN network design.

\subsubsection{Limitations concerning computation capability}

The sensor node has an embedded processor and a storage unit. Because of the unit cost and power limitations of each sensor node, the sensor node's computation ability is very limited. How to utilize the computation ability effectively and process the distributed computation is another important research topic.

\subsubsection{Large quantity of nodes}

There is a large quantity of nodes in a WSN, from several hundred to several million. The sensor nodes are distributed in a large, often harsh sensor field. For this reason, the network routing protocol should be reliable and robust.

\subsubsection{Dynamic network}

A WSN has a strong dynamic property. In order to sense targets, the sensor nodes and the users all have the property of mobility. Because of the energy limitations, the sensor nodes may run out of power. The sensor nodes may lose contact with the network due to radio interference. In light of that, in a practical setting, the network topology of a WSN keeps changing, and so the WSN has to rebuild or adjust by itself. 


\subsection{Performance evaluation of WSNs}

In different applications, WSNs have different structures and topologies, so that the performance of each WSN is quite different. There are several common aspects for evaluating the performance of a WSN.

\subsubsection{Energy efficiency}

Because the sensor nodes are powered by battery, energy efficiency is the most important factor for a WSN. To retain efficiency, technologies such as data fusion are applied. Data fusion is a process that combines all the raw data into a reduced amount of data, keeping most of the information and dumping any that is redundant.

\subsubsection{Lifetime}

The lifetime of a WSN is the period between when the network starts and when it ends. Factors that affect the life cycle include battery volume, antenna type, node position, and routing protocol.

\subsubsection{Time delay}

The time delay is the period between the user inputting a command and the WSN outputting information. The largest factor affecting the time delay is the WSN hardware. 


\subsubsection{Sensing accuracy}

The sensing accuracy of a WSN refers to the precision of the information received by users. The sensing accuracy is affected by the performance of the sensor nodes and the network communication protocols. There is an important relationship among energy efficiency, time delay, and sensing accuracy. These factors have to be considered together in the design of a WSN.

\subsubsection{Fault tolerance}

In practice, sensor nodes probably lose function because batteries are used up or sensors are damaged. The wireless communication channel might experience interference. To ensure the information is transmitted to the user correctly, the WSN must have the ability to self-adapt and rebuild when an individual node malfunctions. 


\section{WSN PROTOCOLS}

This chapter consists of two sections. In the first section, we introduce some typical media access control (MAC) protocols that are related to WSNs, such as TDM-FDMS, MACS, DE-MAC, TRAMA, CSMA/CD, CSMA/CA, S-MAC, and T-MAC.

In the second section, some typical routing protocols will be introduced, such as direct transmission, flooding, gossiping, SPIN, LEACH, and PEGASIS. The direct transmission protocol, the LEACH protocol, and the PEGASIS protocol are compared in different WSNs.

\subsection{WSN MAC protocols}

Several wireless MAC protocols have been developed for traditional ad hoc networks. However, ad hoc networks' MAC protocols are designed to connect the high- mobility nodes and satisfy the quality of service (QoS) requirement. Energy efficiency is not the main problem in ad hoc networks. Therefore, new MAC protocols have been developed for WSNs.

The MAC protocols are classified into two categories, i.e. scheduled protocols and contention-based protocols [12]. 


\subsubsection{Scheduled protocols}

Collision in wireless networks is a basic issue related to channel allocation and multiple access problems. In modem cellular communication systems, many MAC protocols have been developed to help the network manage radio channels. For example, some popular protocols are time division multiple access (TDMA), frequency division multiple access (FDMA) and code division multiple access (CDMA) [13].

Considering the energy efficiency problem, several scheduled MAC protocols have also been developed for WSNs, such as TDM-FDMS, MACS, DE-MAC, and TRAMA. Researchers are developing new energy-efficient scheduled WSN MAC protocols.

\subsubsection{TDMA}

To avoid interference, the time division multiple access (TDMA) protocol divides a radio frequency channel into different sub-channels by time slot. In one time slot, only one user can access this wireless channel to transmit and receive a signal. The TDMA system communicates in a buffer and burst method. Therefore, any user in a TDMA system transmits and receives data non-continuously. Several TDMA applications have been developed for WSNs; for example, Sohrabi and Pottie propose a TDMA protocol for wireless ad hoc sensor networks [17].

Figure 5 shows a TDMA scheme in one period. User \#1 can occupy time slot 1, which includes $0-T_{1}$ and $T_{n}-T_{n+1}$, user \#n can occupy time slot $n$, and so on. 


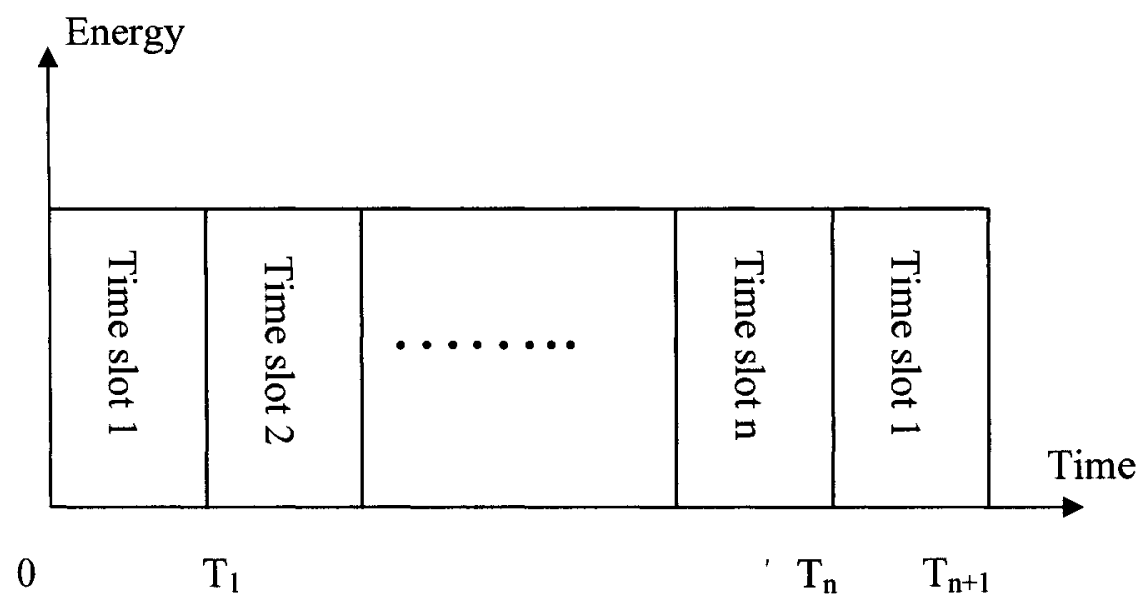

Figure 5: TDMA

\subsubsection{FDMA}

The frequency division multiple access (FDMA) system splits a radio frequency channel into different sub-channels by frequency slot. A guard band is put between the sub-channels to prevent interference. Therefore, users can continuously transmit and receive signals through the sub-channels. However, compared with the TMDA system, the FMDA system wastes bandwidth because of the guard band.

Figure 6 shows the FDMA scheme. User \#1 can occupy sub channel 1, which is allocated from F0 to F1. User \#2 can occupy sub channel 2, which is allocated from F2 to F3. There is a guard band between F1 and F2. 


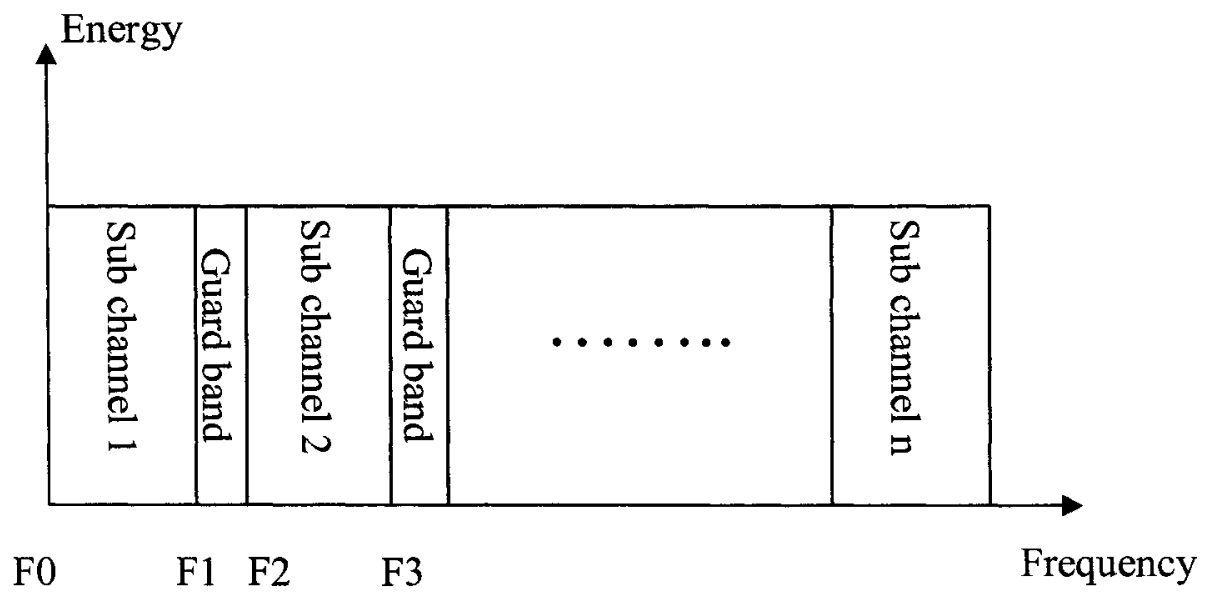

Figure 6: FDMA

\subsubsection{CDMA}

Code division multiple access (CDMA) is a digital communication technique that has been used in military applications. All users are allowed to access the radio frequency channel at the same time and same frequency. To avoid a collision, the narrow bandwidth message signal is multiplied by a large bandwidth signal, which is called the spreading signal. The spreading signal is a pseudo noise code sequence. Each user has a unique pseudo-random code, which is orthogonal to other codes. The receiver processes the signal using a time correlation operation. Given a specific code, the desired signal can be detected, and other signals appear as noise. 


\subsubsection{TDM-FDM}

The TDM-FDM is a hybrid scheme that includes TDMA and FDMA [14]. The communication channel is split into different time slots and different sub channels at the same time.

\subsubsection{SMACS}

SMACS (self-organizing medium access control for sensor networks) is a distributed protocol [12]. TDMA and FDMA are applied in this protocol. When a communication link is set up, the time slot is chosen randomly and the sub channel is fixed.

\subsubsection{DE-MAC}

The DE-MAC (Distributed Energy-aware MAC) protocol causes the sensor nodes to exchange information about the energy that remains [16]. DE-MAC introduces the concept of periodic listen and sleep. A sensor node switches off its radio and goes into sleep mode only when it is in its own time slot and does not have anything to transmit. The node has to keep the radio awake in the slots assigned to its neighbors in order to receive packets from them. It also uses a leader election process to allow low-energy nodes to sleep more than higher-energy nodes. A "winner" sensor node, a node with the lowest remaining energy, is chosen. The "winner" has more standby time than the neighbor nodes. In this way, the sensor nodes consume energy evenly and the lifetime of the WSN is prolonged. 


\subsubsection{TRAMA}

Rajendran, Obraczka et al. propose a TRAMA (traffic-adaptive medium access) protocol [18]. The TRAMA protocol chooses the nodes that can transmit information in an allocated time slot, using the traffic information of each node, and avoids collisions with the use of a traffic schedule. Nodes with no transmit/receive task will sleep. Compared to contention-based protocols, the TRAMA protocol reaches a higher throughput, but it has a longer time delay. This protocol is more suitable for applications that do not require a fast response.

\subsubsection{Contention-based protocols}

As opposed to the scheduled protocols, the contention-based protocols do not split the communication channel into sub channels or time slots for each user. Therefore, all users use a common channel. A contention mechanism is applied to decide which user has the right to access the channel. The most typical contention-based protocol is $\mathrm{CSMA} / \mathrm{CA}$ (carrier sense multiple access with collision avoidance).

Contention-based protocols have some advantages compared to scheduled protocols. First, in a WSN, the sensor nodes access wireless channels by contention. The resources are allocated on demand. Second, when topologies change, contention-based protocols are 
more flexible than scheduled protocols. Finally, contention-based protocols do not need the fine-grained time synchronization required by the scheduled protocols.

On the other hand, contention-based protocols have a disadvantage. Because all users use the same channel at the same time, some energy is used for contention for the media and wasted on collisions, leading to inefficient usage of energy. If the contention-based protocols are to be applied to a WSN, this disadvantage has to be overcome.

Some contention-based protocols are introduced below.

\subsubsection{CSMA/CD}

The carrier sense multiple access with collision detection (CSMA/CD) protocol has been adopted by the IEEE 802.3 Ethernet standard. The term "multiple access" means that more than one user shares a carrier, which is usually a communication channel. The term "carrier sense" means that each user on the network has to listen to ascertain whether the carrier is occupied before transmitting data. If the carrier is idle, the data will be transmitted immediately. If another user occupies the carrier, the user that wants to transmit data has to wait. If two users find the carrier is idle and begin to transmit data at same time, a collision happens. To avoid collisions, a collision detection technique is applied. The collision detection technique means that users keep listening to the carrier while transmitting data. When a collision is detected, the users involved stop transmitting and resume transmitting after a random waiting time. 


\subsubsection{CSMA/CA}

There is a hidden terminal problem in a multi-hop wireless network [21]. This problem causes additional collisions in wireless networks that use the CSMA/CD protocol. To solve this problem, the CSMA/CA (carrier sense multiple access for collision avoidance) protocol was developed and adopted by the wireless LAN protocol standard, IEEE $802.11[22]$.

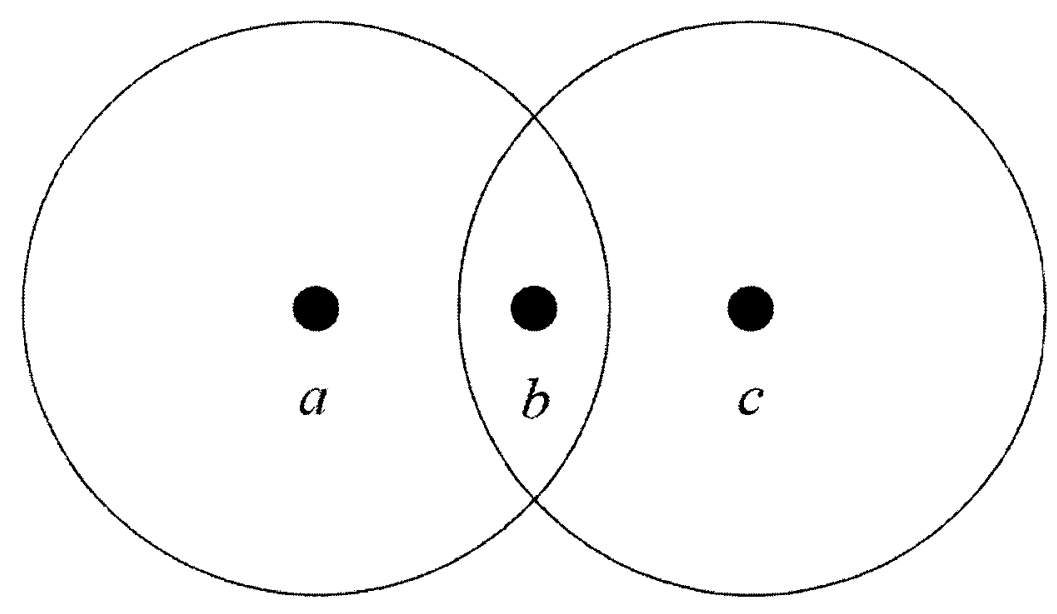

Figure 7: Hidden terminal problem

Figure 7 shows the hidden terminal problem [21]. Because of the maximum wireless communication distance, nodes "a", "b" and "c" can only communicate with their 
adjacent neighbors. Node "a" can hear node "b" and node "b" can hear node "c". Node "a" cannot hear node "c". When node "a" is transmitting data to node "b," node "c" does not hear it, and its carrier sense still indicates that the media is idle. If node " $c$ " begins transmitting, node " $b$ " will receive colliding packets from node "a" and " $b$ " at the same time.

In CSMA/CA, a handshake between a sender and a receiver is established before the sender transmits data. When the handshake begins, the sender sends a Request-to-Send (RTS) packet to the receiver. After receiving the RTS packet, the receiver sends a Clear-to-Send (CTS) packet. An RTS-CTS handshake is set up to make an announcement to the neighbors of both the sender and the receiver. In Figure 7, node " $\mathrm{c}$ " cannot hear the RTS packet from node "a," but node "c" can hear the CTS packet from node "b". If a node hears an RTS packet or CTS packet that is being sent to other nodes, this node should not send out its own packet. This helps to reduce the energy lost from collisions caused by the hidden terminal problem.

\subsubsection{S-MAC}

To improve the energy efficiency of WSNs, W. Ye et al. introduced the S-MAC (Sensor-MAC) protocol in 2002 [19]. Some techniques from the IEEE 802.11 standard were adopted in the S-MAC protocol, such as carrier sense and RTS/CTS. 
Several new techniques have been applied to meet the requirement for energy efficiency. First, all sensor nodes sleep periodically. Second, all sensor nodes are separated into several clusters. Each cluster is synchronized. Compared with the protocol in the IEEE 802.11 standard, S-MAC has greater energy efficiency properties and deals with the tradeoff between energy and time delay.

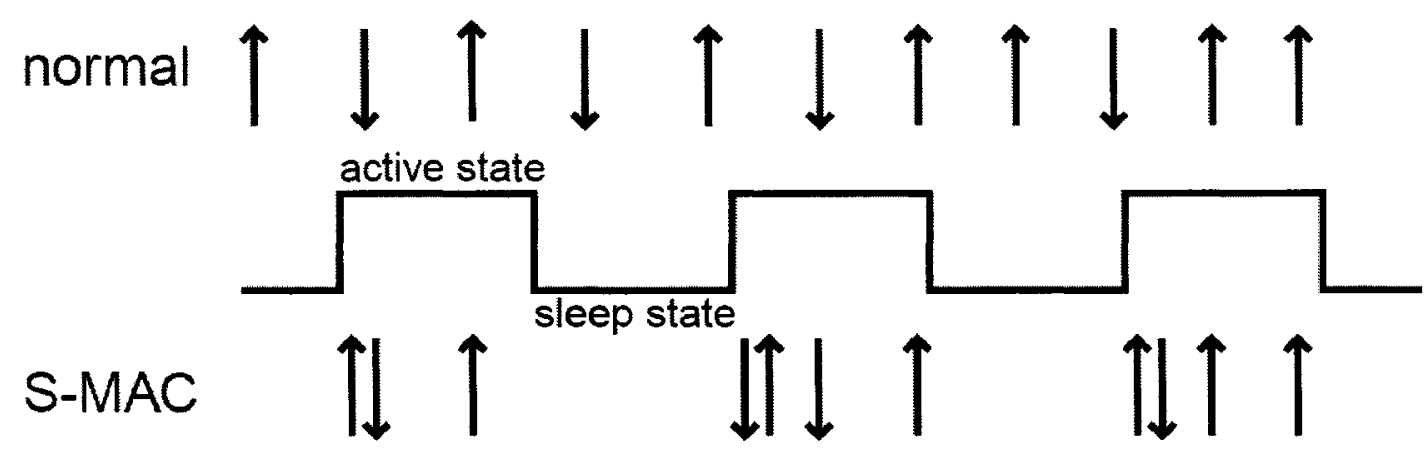

Figure 8: The S-MAC duty cycle

Figure 8 shows the S-MAC duty cycle [20]. The arrows indicate the transmitted and received packets. Differing from traditional contention-based protocols, S-MAC has two states over time. One state is the active state and the other state is the sleep state.

During the active state, a sensor node can open its transmitter and send/receive messages queued in the sleep state. During the sleep state, a sensor node turns off its radio to save energy. 
The advantage of S-MAC is that the energy used for listening is saved in the sleep state. The disadvantage of S-MAC is that the throughput is reduced and latency is increased.

\subsubsection{T-MAC}

T. van Dam and K. Langendoen introduced the T-MAC (Timeout-MAC) protocol in 2003. The main mechanism of T-MAC is to apply an adaptive duty cycle. All messages are transmitted in bursts, so that the active time is variable. To maintain an optimal active time under a variable load, the active time will be ended if nothing is heard within a fixed period [20].

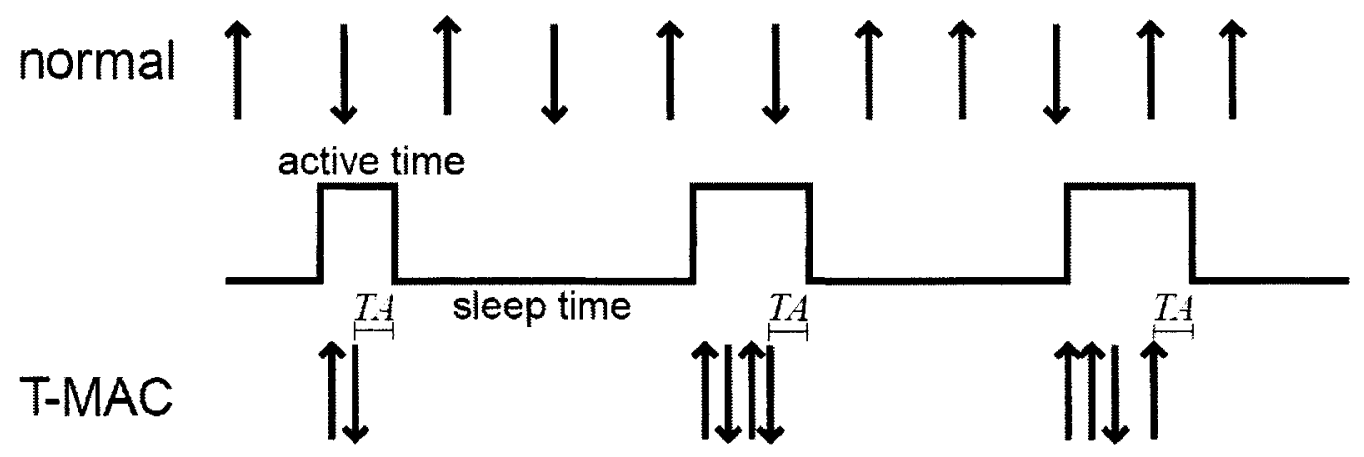

Figure 9: The T-MAC duty cycle 
Figure 9 shows the T-MAC duty cycle [20]. The arrows indicate the transmitted and received packets. Similar to the S-MAC protocol, T-MAC has two timed states: the active time state and the sleep time state.

During the active time state, a sensor node can open its transmitter and send/receive messages queued in the sleep time state. All the messages are sent or received in bursts. After the messages have been sent or received, the sensor node listens to the channel. If nothing is heard within a fixed period, which is shown as TA in Figure 9, the sensor node will move into the sleep time stage.

Compared with CSMA, which has no duty cycle, and S-MAC, which has a fixed duty cycle, T-MAC can reduce the amount of energy wasted on idle listening.

\subsubsection{Overview of WSN MAC protocols}

In summary, the scheduled protocols provide robust communication channels. Given a reliable schedule, these protocols are perfectly capable of avoiding collisions. However, most of the scheduled protocols require global network information to produce a reliable schedule. Therefore, they are harder to implement than contention-based protocols.

The contention-based protocols reduce collision and greatly preserve energy. However, network latency is increased. A WSN that applies contention-based protocols cannot 
satisfy real-time requirements, but can be used in applications that focus on slow-changing information, such as a weather monitoring system.

\subsection{WSN routing protocols}

WSN routing protocols are classified into two categories according to the network topology: flat routing protocols and hierarchical routing protocols.

\subsubsection{Flat routing protocols}

\section{Definition of flat routing protocols in Ethernet networks}

Flat routing protocols distribute information as needed to any router that can be reached or receive information. No effort is made to organize the network or its traffic. It just discovers the best route, hop by hop, to a destination, along any path. All routers are peers of all others, as all routers sit on a flat geometric plane. The Routing Information Protocol (RIP) is an example of a flat routing protocol [23].

In a WSN, one of the functions of sensor nodes is routing. Figure $\mathbf{1 0}$ shows a general WSN sensor nodes route, running flat routing protocols. In this figure, the sensor nodes send information packets to the base station by multi-hop. 


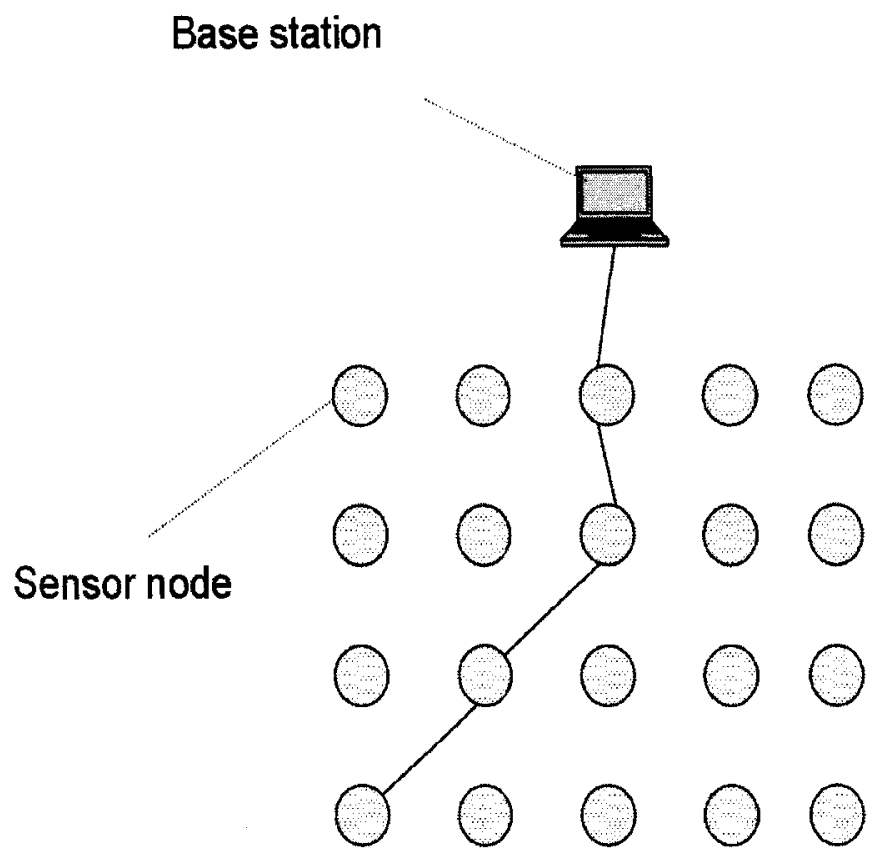

Figure 10: Flat routing protocols

Many flat routing protocols are applied in WSNs, such as direct transmission, flooding, and SPIN (Sensor Protocol for Information via Negotiation).

\subsubsection{Direct transmission}

Direct transmission is a basic routing protocol. All sensor nodes simply transmit their information directly to a base station. This protocol is used for situations where the neighbor sensor nodes are unknown. 


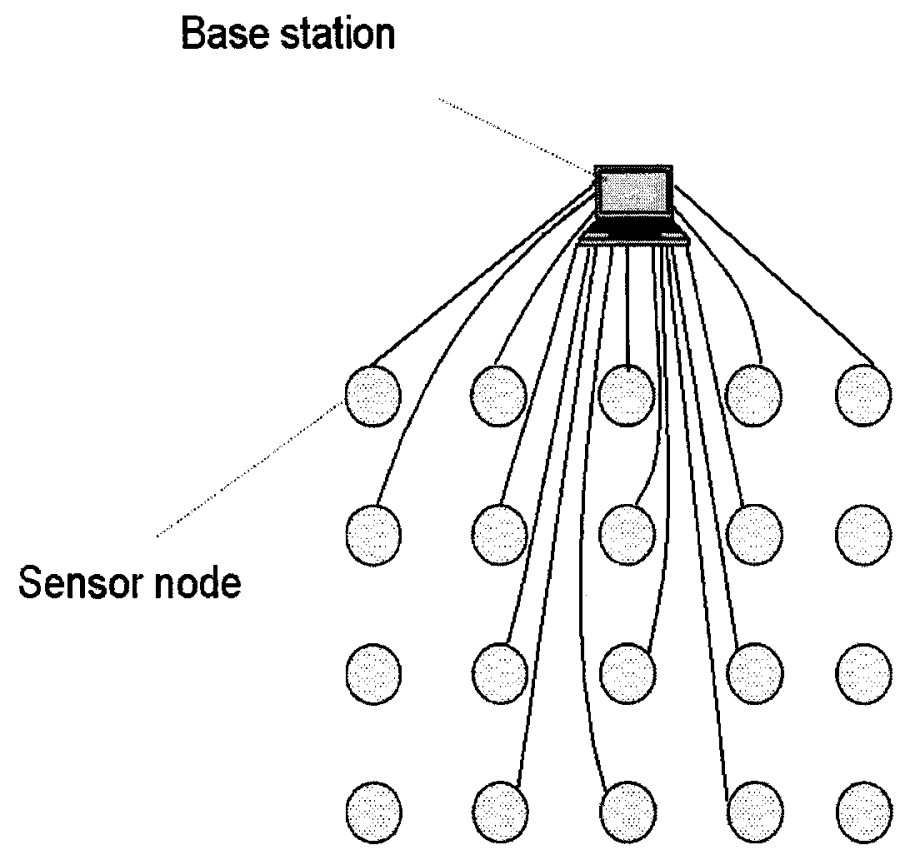

Figure 11: Direct transmission

Figure 11 shows the direct transmission protocol. In this protocol, all sensor nodes are supposed to be in the maximum communication range between the sensor nodes and the base station.

The advantages of this protocol are that it is easy to implement and has a short time delay. The disadvantages of this protocol is that sensor nodes that are far from the base station consume too much energy when transmitting information packets and the network size will reduce quickly, due to the death of sensor nodes at the edge of the WSN. 


\subsubsection{Flooding}

In some applications, some sensor nodes are out of the maximum communication range. These sensor nodes cannot transmit or receive information packets to or from the base station; thus the flooding protocol is applied. In this protocol, a sensor node transmits the information packet to all neighbors. When a sensor node receives an information packet from a neighbor, it forwards the packet to all its neighbors by broadcasting. The information packet will stop being forwarded when it reaches the maximum hop.

The advantages of this protocol are that it is easy to implement and disregards the topology of the WSN. However, Hedetniemi and Liestman found that the flooding protocol has two critical problems, which are implosion and overlap [24]. 


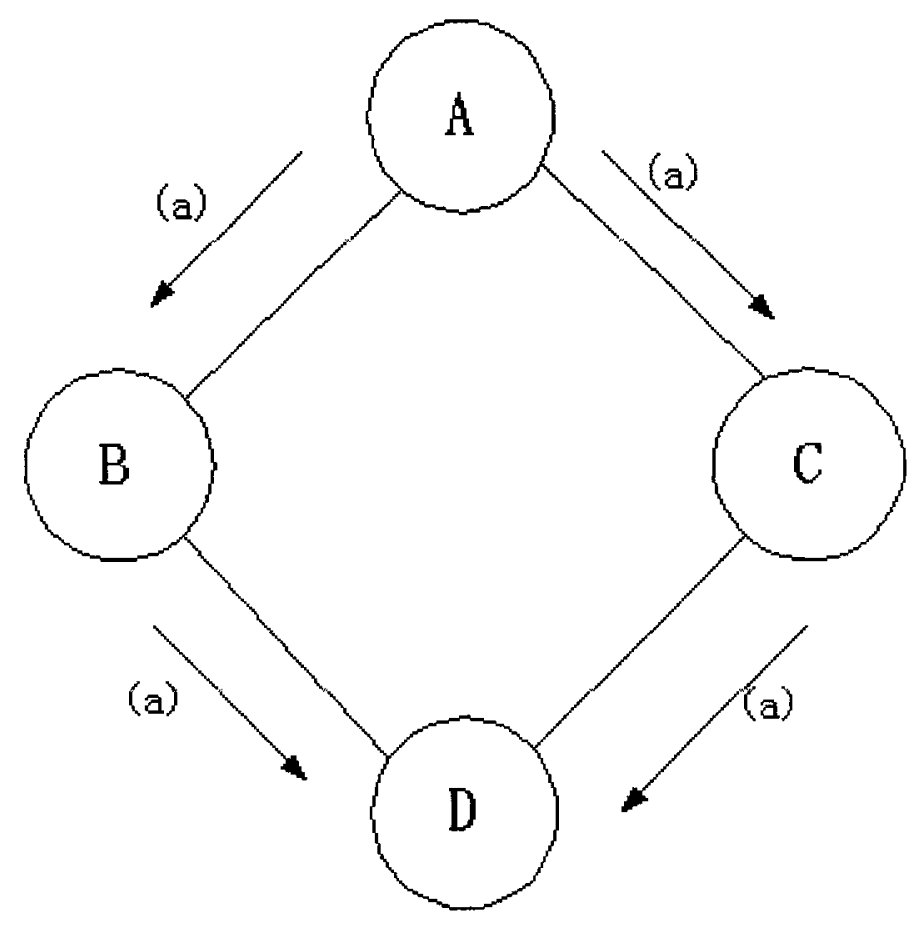

Figure 12: Implosion

Figure 12 shows a phenomenon called implosion. The information packets broadcasted by sensor node $\mathrm{A}$ are received by sensor node $\mathrm{B}$ and sensor node $\mathrm{C}$. Following the flooding protocol, sensor node B and sensor node $\mathrm{C}$ send the received packets to all their neighbors. Sensor node $\mathrm{D}$, which is the common neighbor of sensor nodes $\mathrm{B}$ and $\mathrm{C}$, receives the repeated packets. This repeated transmission causes inefficiency. 


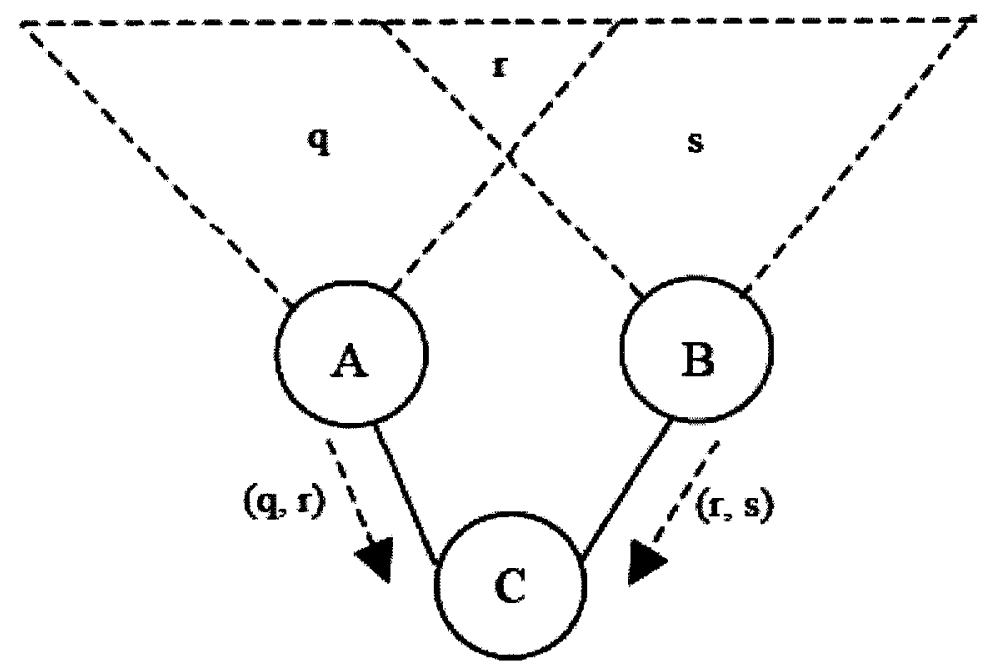

Figure 13: Overlap

Figure 13 shows another phenomenon, called overlap. This phenomenon is a mutation of implosion. Sensor node A receives information packets from sensor nodes located in sensor areas " $q$ " and " $r$ ". Sensor node B receives information packets from sensor nodes located in sensor areas "s" and " $r$ ". Sensor nodes A and B send these packets to sensor node C. In sensor node C, the information packets from sensor area " $r$ " overlap. The information packets from sensor area " $r$ " are transmitted twice, thus energy is wasted.

\subsubsection{Gossiping}

Hedetniemi and Liestman proposed the Gossiping protocol to reduce implosion and overlap in the flooding protocol [24]. The basic idea is that a sensor node only forwards a received information packet to one of its neighbors, which is selected randomly. For 
example, in Figure 12, sensor node B forwards the packets it has received to a randomly selected neighbor. Suppose the probability of selecting sensor node D as the forwarding target is $P=10 \%$, the probability of sensor node $D$ being selected by sensor nodes $B$ and $C$ at the same time is $\mathrm{P}^{2}=1 \%$. Therefore, implosion only appears at $1 \%$ probability. In this way, the implosion and overlap problems are almost solved.

\subsubsection{SPIN}

The SPIN (Sensor Protocol for Information via Negotiation) protocol was introduced by Heinzelman and Balakrishnan in [25]. In this protocol, Heinzelman and Balakrishnan use meta-data, which is a very short message and has low energy consumption. The meta-data includes different messages: ADV, REQ and DATA. Before large amounts of sensing data are transmitted over the network, the ADV and REQ messages negotiate between the sender and receiver. Through the use of a short, quick handshake, the sending of large amounts of data to unnecessary nodes can be avoided. In this way, the protocol satisfies the requirement of energy efficiency.

\subsubsection{Hierarchical routing protocols}

\section{Definition of hierarchical routing protocols in Ethernet networks}

Hierarchical routing protocols often group routers together by function into a hierarchy. A hierarchical protocol allows an administrator to make the best use of the fast, powerful routers as backbone routers, and the slower, 
lower-powered routers may be used for access purposes. In this way, the access routers form the first tier of the hierarchy, and the backbone routers form the second tier. Hierarchical protocols make an effort to keep local traffic local; that is, they will not forward traffic to the backbone if it is not necessary to reach a destination. Some hierarchical protocols also perform route aggregation to reduce the number of routes advertised (only summary routes are advertised). Connections and data flow through the access routers, and only enter the backbone when trying to reach distant parts of the network that have no local connections other than the backbone routers. This allows traffic to flow freely locally, and concentrates long-distance data onto the backbone links to flow efficiently to the opposite side, minimizing congestion. Open Shortest Path First (OSPF) and Intermediate-system to Intermediate-System (IS-IS) are two routing protocols that can be configured to organize a network hierarchically [23]. 


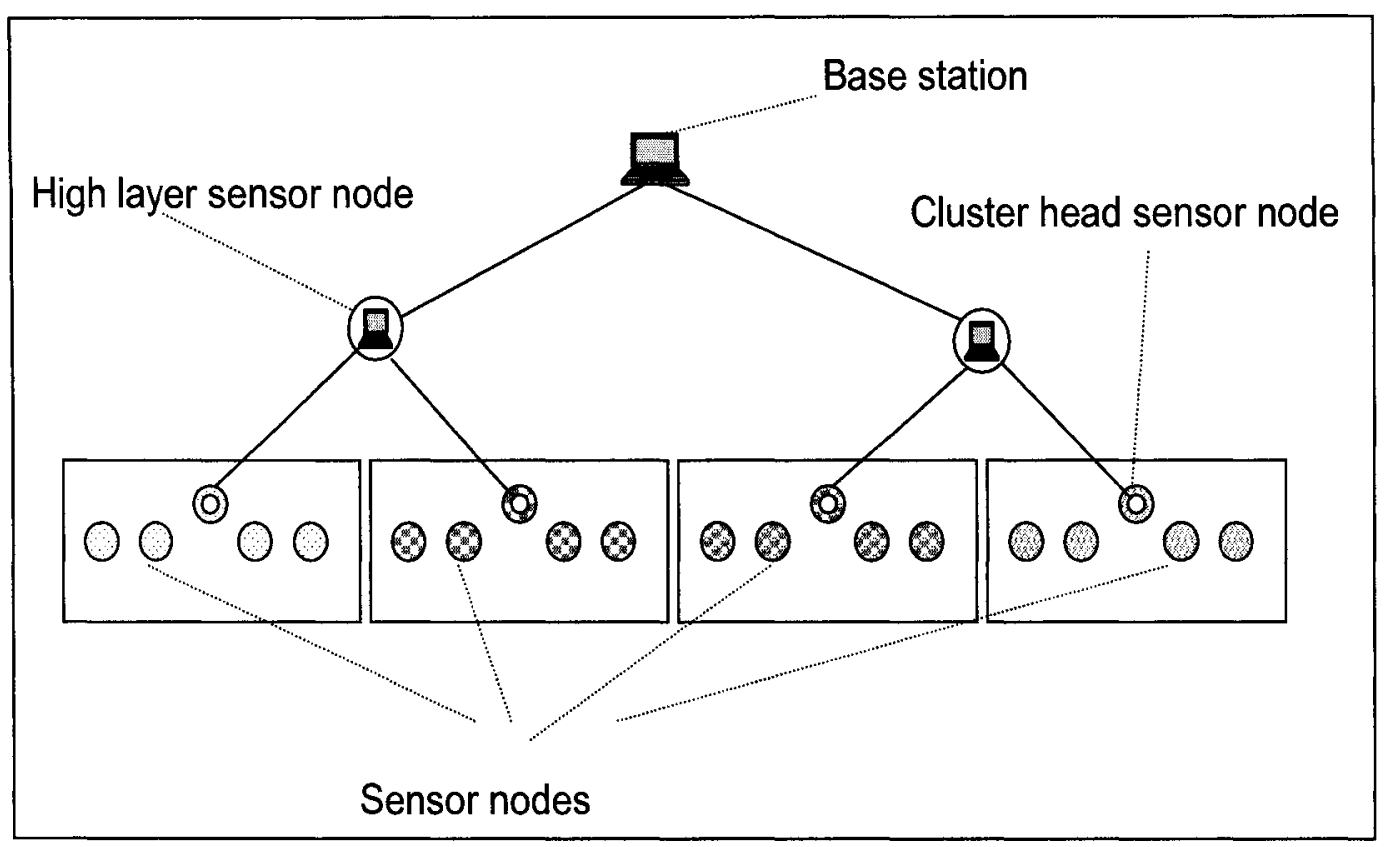

Figure 14: Hierarchical routing protocols

Figure 14 shows the hierarchical routing protocols. All sensor nodes are classified into multi-layers. The sensor nodes in the lowest layer are classified into clusters. In each cluster, there are sensor nodes and a cluster head sensor node. The sensor nodes connect to the cluster head sensor nodes only. The cluster head sensor nodes connect with the higher layer sensor nodes and the normal sensor nodes as bridges. The higher layer sensor nodes connect the base station and the cluster head sensor nodes as backbones.

Many hierarchical routing protocols have been developed for WSNs, such as LEACH and PEGASIS. 


\subsubsection{LEACH}

Heinzelman not only introduced a flat routing protocol, SPIN [25], but also developed a hierarchical protocol, LEACH (Low-Energy Adaptive Clustering Hierarchy) [26]. In this protocol, some assumptions are made. First, the sensor nodes can adjust their power level according to distance from the receiver. Second, every sensor node has the ability to send data directly to the base station, which is far away from the sensor area. Finally, sensor nodes have limited energy.

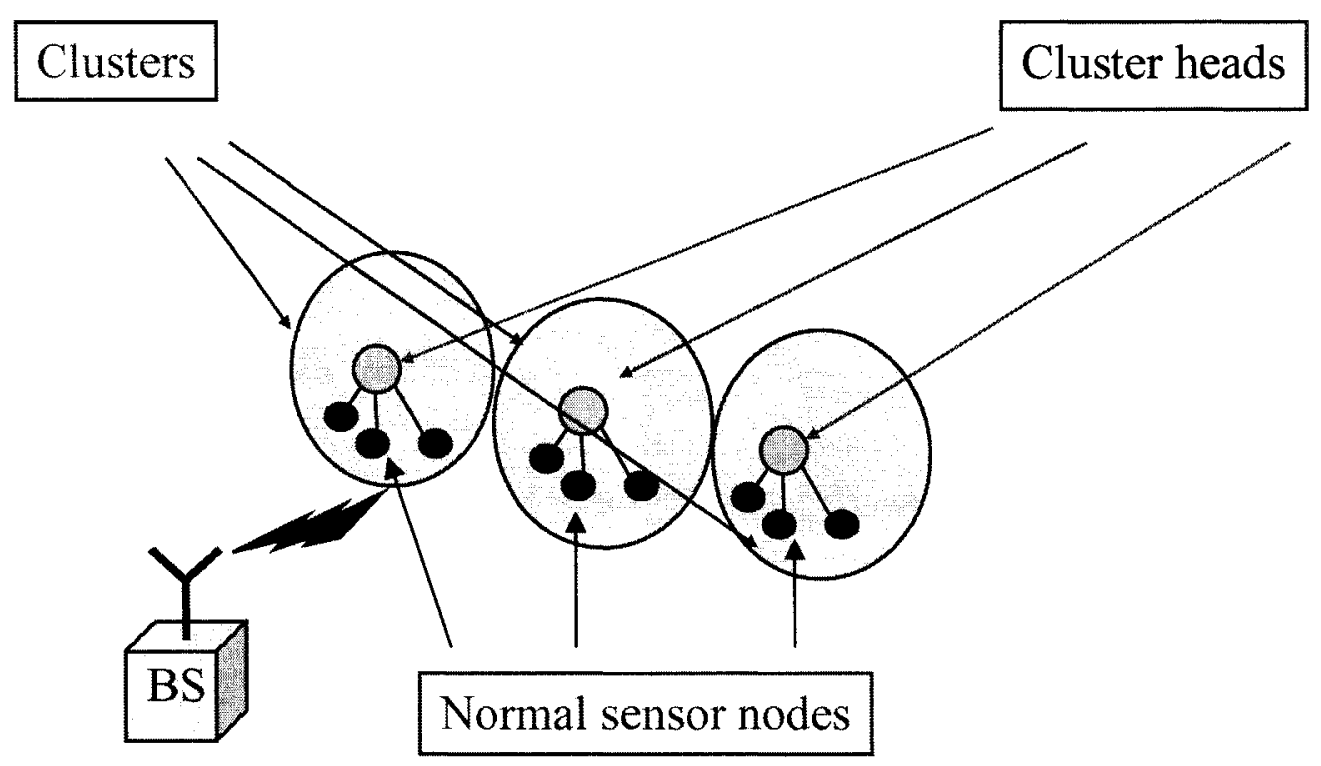

Figure 15: LEACH

As shown in Figure 15, the LEACH protocol hives off nearby sensor nodes into the same cluster. In each cluster, a sensor node called the cluster head collects, aggregates and sends the data to the base station directly. When performing cluster head tasks, the cluster 
head sensor nodes consume much more energy than other normal sensor nodes in the cluster. To extend the lifetime of the network and avoid the quick death of certain sensor nodes (the cluster heads), the cluster head is randomly selected in every data collection round. A sensor node $n$ promotes itself as the cluster head when it generates a random number between 0 and 1 , which is bigger than the a priori decided threshold $T(n)$.

$$
T(n)=\left\{\begin{array}{cc}
\frac{P}{1-P^{*}\left[r^{*} \bmod (1 / p)\right.} & n \in G \\
0 & n \notin G
\end{array}\right.
$$

In equation (3.1), T (n) is the threshold for sensor node $n . P$ is the desired percentage of cluster heads in the network. $r$ is the current round, and $G$ is the set of sensor nodes that have not been selected as a cluster head in the last $1 / \mathrm{P}$ round. According to the power consumption formula and the size and density of the sensor network, the parameters must be selected carefully to provide high-level performance.

One of the disadvantages of this protocol is that the random selection of cluster heads cannot ensure that they are ideally and evenly scattered throughout the network. Thus some nodes may still require long-distance transmission.

Another disadvantage is that since the parameter is decided a priori, when the sensor nodes gradually die out and the network changes, the existing best parameters are often not the best anymore. 


\subsubsection{PEGASIS}

Lindsey and Raghavendra proposed a chain-based PEGASIS (Power-Efficient Gathering in Sensor Information System) [27, 28]. This protocol conserves energy by shortening the transmission range and lessening the number of sensor nodes that communicate with a distant base station. As shown in Figure 16, beginning at the sensor node furthest away from the base station, every node finds its nearest neighbour that has not joined the chain. A chain is made of all the sensor nodes by the greedy algorithm, which is also called the nearest neighbour algorithm. With the assumption that every sensor node has identical, current global information, the output of each node is the same. After the chain has been set up, each node communicates only with its direct neighbour in the chain. Every sensor node in the chain also performs data fusion for its own data and that of its neighbours. Thus, every sensor node sends an information packet of equal size. The chain is constructed before the first round of communication. In each data-gathering round, a sensor node is selected as the chain leader in sequential order, and transmits the fused data to the base station. When a sensor node dies, the chain is reconstructed. 


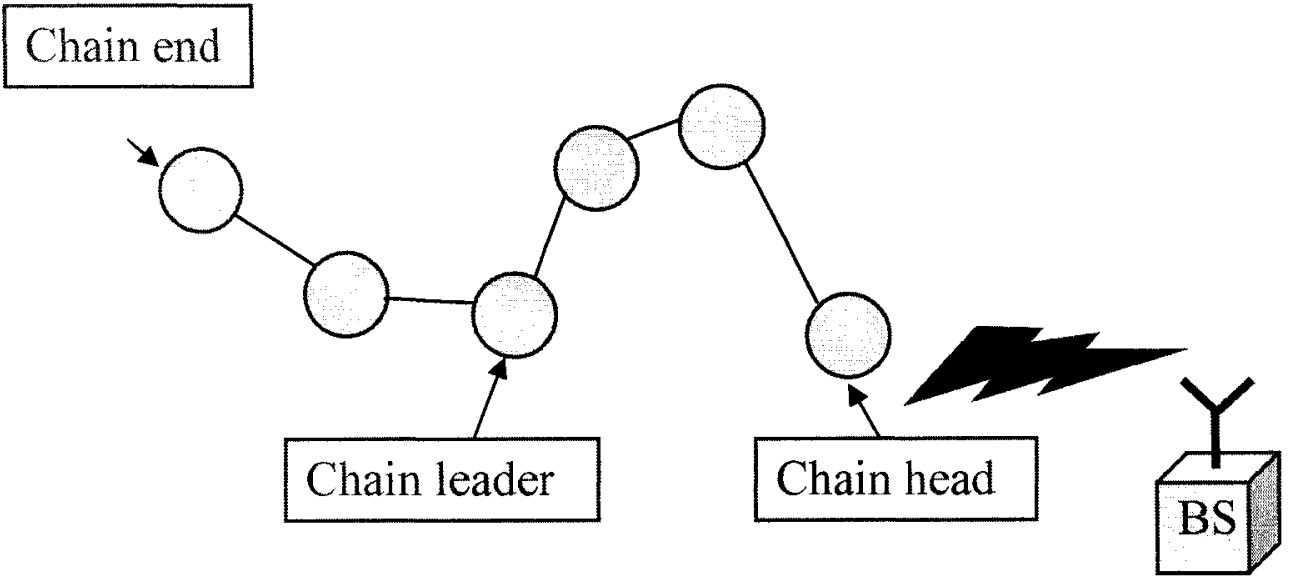

Figure 16: PEGASIS

The advantages of PEGASIS are:

- The transmission distances are minimized.

- The number of sensor nodes that must send packets to the base station is minimized (only one chain leader in a chain sends packets to the base station).

- The number of packets that the chain leader has to receive is minimized.

- The workload is distributed more equally among the sensor nodes.

All chain-based routing protocols have these advantages. 
In practice, Lindsey compared the power consumption of the direct transmission protocol, LEACH protocol and PEGASIS protocol in a real-world WSN. Figure 17 shows the simulation results of [27]. Lindsey found that the WSN that applied the PEGASIS protocol has a lifetime 2 to 3 times longer than the WSN that applied the LEACH protocol, and from 10 to 25 times longer than the WSN that applied the direct transmission protocol. In this simulation, 100 sensor nodes were randomly scattered over a $50 \mathrm{~m}$ X 50m sensor field. The sensor nodes had the same amount of energy, i.e. $0.25 \mathrm{~J}$. Applying the direct transmission protocol, all the sensor nodes died in the $61^{\text {st }}$ round of data gathering. With the LEACH protocol, all the sensor nodes died in the $576^{\text {th }}$ round of data gathering. Under the PEGASIS protocol, all the sensor nodes died in the $1,544^{\text {th }}$ round of data gathering. 


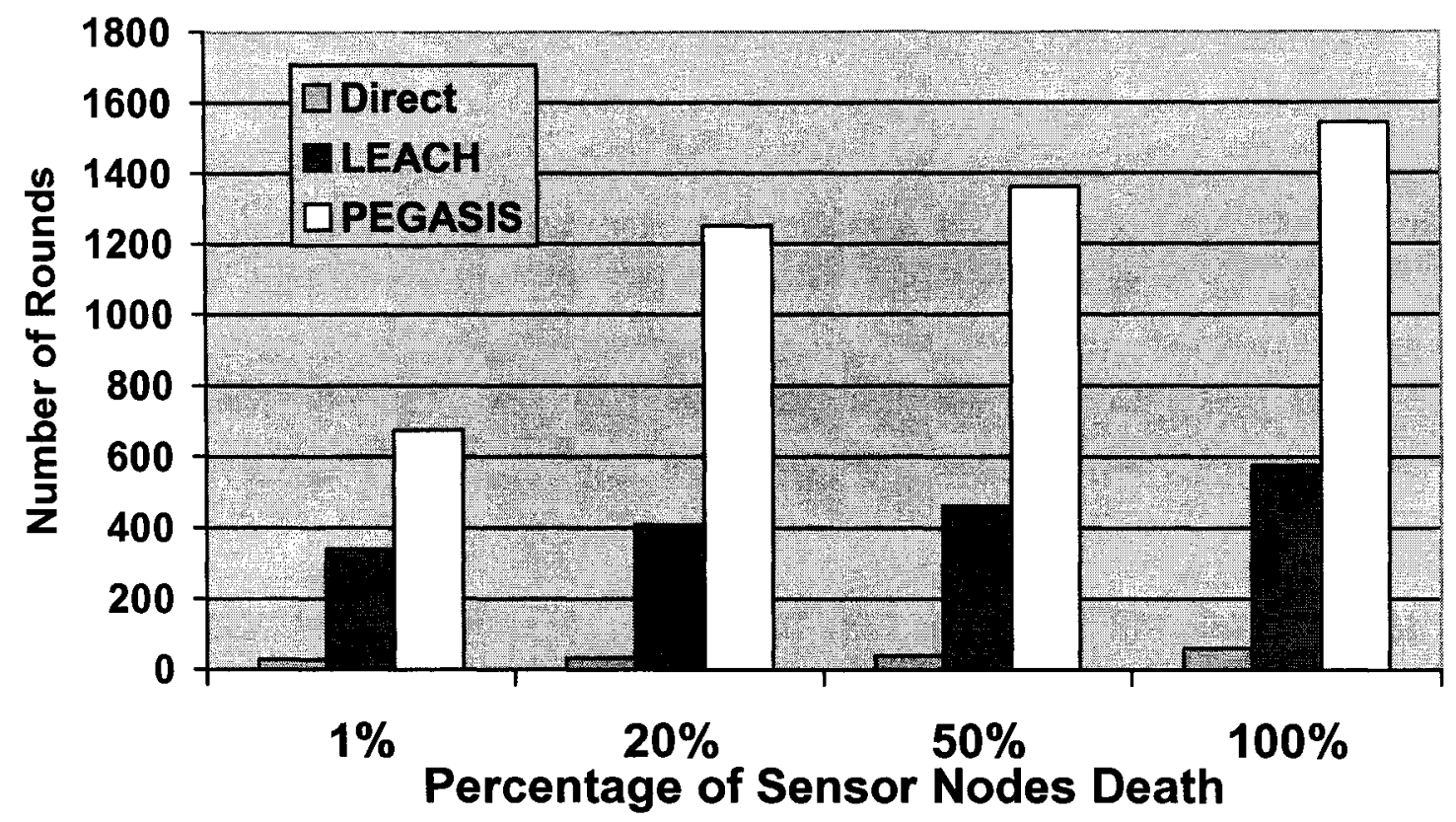

Figure 17: Lifetime of a WSN

\subsubsection{A four-sensor-node WSN}

In Lindsey's simulation [27], PEGASIS was the protocol that consumed the least energy in a WSN with 100 sensor nodes, because of the advantages of the chain-based protocol. However, in a small-scale WSN with a centralized base station, the result is different. Figure 18 shows an extreme example. There are only four sensor nodes, which form a square. The base station is in the centre of the sensor nodes. All sensor nodes are an equal distance "d" away from the base station. In this four-sensor-node WSN, the total transmission distance is $4 d$ when the direct transmission protocol is applied. 


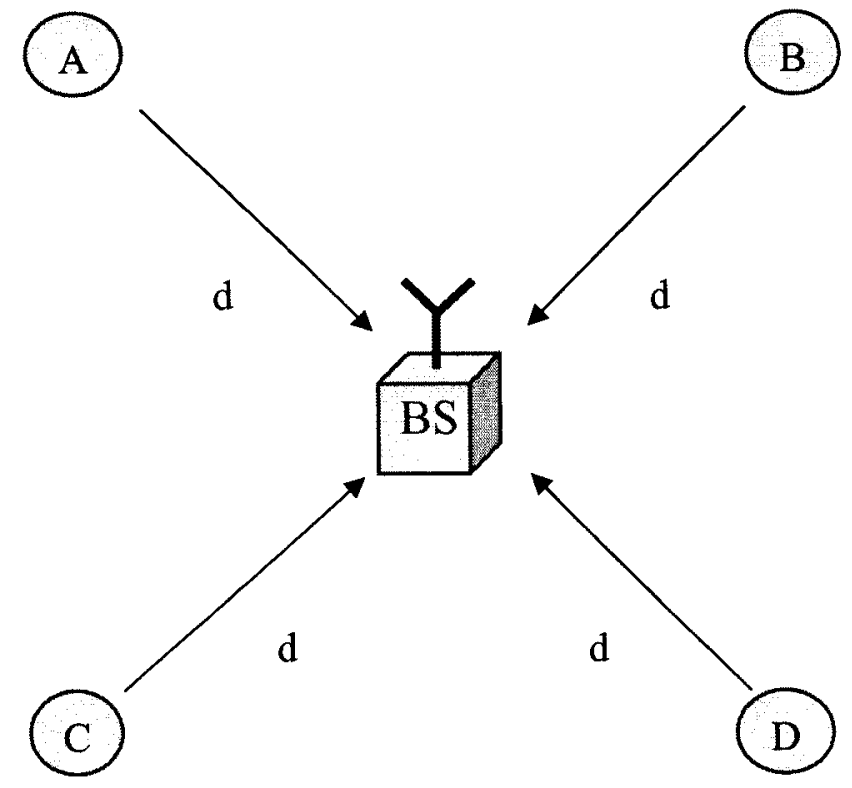

Figure 18: Direct transmission in a four-sensor-node WSN

As shown in Figure 19, the LEACH protocol is applied in the same WSN. The total transmission distance is $(2+2 \sqrt{2}) d$ 


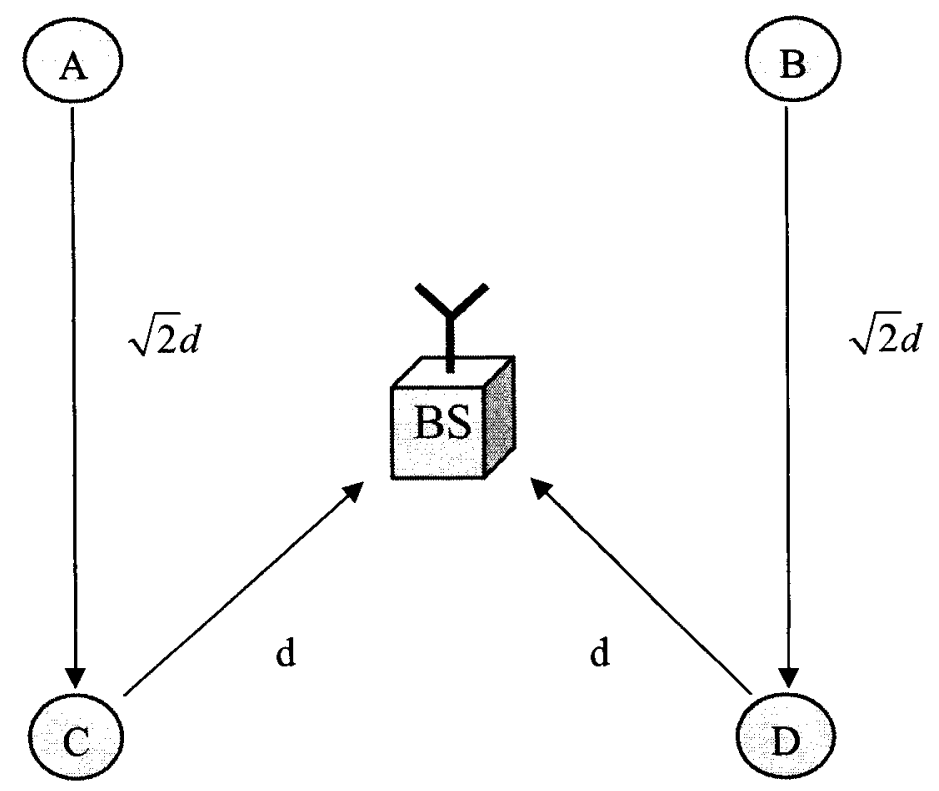

Figure 19: LEACH in a four-sensor-node WSN

As shown in Figure 20, the PEGASIS protocol is applied. The total transmission distance is $(1+3 \sqrt{2}) d$. 


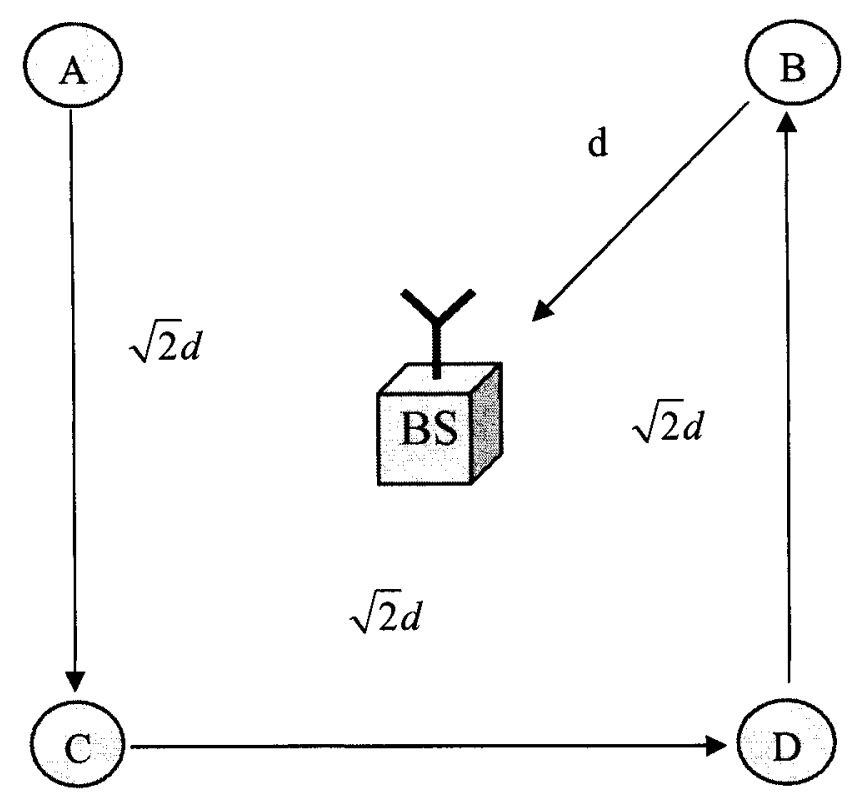

Figure 20: PEGASIS in a four-sensor-node WSN

We assume these four sensor nodes and base station are in a flat plane and the wireless signal is transmitted in free space. Therefore, we can calculate the energy consumption ratio between three protocols.

According to the radio propagation model [29], the received power of the signal decreases as the distance between the transmitter and the receiver increases. From the free space equation, the transmit power is attenuated in proportion with the square of the distance between the sender and the receiver.

$$
P_{r}=\frac{P_{t} G_{t} G_{r} \lambda^{2}}{(4 \pi d)^{2}}
$$


The free space equation is (3.2), where $P_{r}(d)$ is the receive power; $P_{t}$ is the transmission power; $G_{t}$ and $G_{r}$ are the gain of the transmitting and receiving antenna; $\lambda$ is the wavelength of the carrier signal; and $d$ is the distance between transmitter and receiver. From equation (3.2), we get

$$
P_{t}=\frac{P_{r}(4 \pi d)^{2}}{G_{t} G_{r} \lambda^{2}}
$$

We assume each sensor node has the same $G_{t}, G_{r}$ and $\lambda$. To minimize transmission power, we apply power control technology, which reduces the transmission power until $\mathrm{P}_{\mathrm{r}}$ reaches the minimum requirement. Assuming each sensor node has the same $P_{r}$, we can calculate the total power of a four-sensor-node WSN under different protocols.

$$
P_{\text {total }}=\sum_{n o d e=D}^{A} \frac{P_{r}(4 \pi d)^{2}}{G_{t} G_{r} \lambda^{2}}
$$

From Figure 18, we get

$$
P_{\text {total }}(\text { Direct })=4 \frac{P_{r}(4 \pi d)^{2}}{G_{t} G_{r} \lambda^{2}}
$$

From Figure 19, we get

$$
P_{\text {total }}(L E A C H)=6 \frac{P_{r}(4 \pi d)^{2}}{G_{t} G_{r} \lambda^{2}}
$$

From Figure 20, we get

$$
P_{t o t a l}(P E G A S I S)=7 \frac{P_{r}(4 \pi d)^{2}}{G_{t} G_{r} \lambda^{2}}
$$


Therefore, in unit time, the total power consumption ratio of the three protocols in this four-sensor-node WSN is $P_{\text {total }}($ Direct $): P_{\text {total }}\left(\right.$ LEACH): $P_{\text {total }}($ PEGASIS $)=4: 6: 7$.

\subsubsection{Overview of WSN routing protocols}

In summary, in a WSN that has several sensor nodes, the flat routing protocols have the advantages of high-energy efficiency and short latency time. However, when the number of sensor nodes increases to dozens or hundreds, the flat routing protocols consume much more energy than the hierarchical protocols.

Table 1 shows a comparison of the direct transmission, LEACH and PEGASIS protocols. Of the hierarchical protocols, chain-based protocols have greater energy efficiency than the clustering protocols. Within the chain-based protocols, the chain formation algorithm is the best option for energy efficiency. 
Table 1: Comparison of direct transmission, LEACH and PEGASIS protocols

\begin{tabular}{|c|c|c|c|c|}
\hline \multicolumn{2}{|c|}{} & Direct & LEACH & PEGASIS \\
\hline \multirow{2}{*}{$\begin{array}{c}\text { Energy } \\
\text { efficiency }\end{array}$} & 4 nodes & High & Medium & Low \\
\cline { 2 - 6 } & 100 nodes & Low & Medium & High \\
\hline \multirow{2}{*}{\begin{tabular}{c} 
Lifetime \\
\cline { 2 - 6 }
\end{tabular}} & 100 nodes & Short & Medium & Short \\
\hline \multirow{2}{*}{$\begin{array}{c}\text { Latency } \\
\text { time }\end{array}$} & 4 nodes & Short & Short & Long \\
\cline { 2 - 6 } & 100 nodes & Short & Short & Long \\
\hline
\end{tabular}

Forming a chain in a number of sensor nodes is a typical traveling salesman problem (TSP). Lindsey applies the greedy algorithm to form a routing chain [27]. However, some other algorithms perform better than the greedy algorithm. Therefore, a new WSN routing protocol that uses other algorithms might perform better than PEGASIS. 


\section{TRAVELING SALESMAN PROBLEM AND SIMULATED ANNEALING ALGORITHM}

There are five sections in this chapter. The first section introduces the traveling salesman problem (TSP), which is related to the formation of a WSN communication routing chain.

The second section introduces the combination optimization problem and some algorithms for solving this problem.

In the third section, the simulated annealing algorithm will be discussed; this can approximately solve TSP within an acceptable computation time.

A simulated annealing algorithm is illustrated in the fourth section, through an example that solves a 100-city TSP.

In the fifth section, an SA chain protocol for WSN data gathering and communication is developed. 


\subsection{Traveling salesman problem}

\subsubsection{Definition of traveling salesman problem}

The traveling salesman problem (TSP) is as follows: Given a finite number of "cities," along with the cost of travel between each pair of cities, find the cheapest way of visiting all the cities and returning to the starting point. The travel costs are symmetrical in the sense that traveling from city $\mathrm{X}$ to city $\mathrm{Y}$ costs just as much as traveling from $\mathrm{Y}$ to $\mathrm{X}$; the "method of visiting all the cities" is simply the order in which the cities are visited. To put it differently, the data consist of integer weights assigned to the edges of a finite complete graph; the objective is to find a Hamiltonian cycle (that is, a cycle passing through all the vertices) of the minimum total weight. In this context, Hamiltonian cycles are usually called tours.

\subsubsection{Definition of a Hamiltonian cycle}

In graph theory, a Hamiltonian path is a path in an undirected graph that visits each vertex exactly once. A Hamiltonian cycle is a cycle in an undirected graph that visits each vertex exactly once and also returns to the starting vertex. Determining whether such paths and cycles exist in graphs is the Hamiltonian path problem. Hamiltonian paths and cycles were named after William Rowan Hamilton, who invented the icosian game, now also known as Hamilton's puzzle, which involves finding a Hamiltonian cycle in the edge 
graph of the dodecahedron. Hamilton solved this problem using the icosian calculus, an algebraic structure based on roots of unity with many similarities to the quaternions (also invented by Hamilton). Unfortunately, this solution does not generalize to arbitrary graphs $[34,35]$.

\subsubsection{Studies in TSP}

Mathematical problems related to the TSP were solved in the 1800 s by Irish mathematician William Rowan Hamilton, and by British mathematician Thomas Pennington Kirkman. A discussion of the early work of Hamilton and Kirkman can be found in a book entitled Graph Theory [31].

The general form of the TSP appears to have first been studied in the 1930s by Karl Menger at Harvard. The problem was later promoted by Hassler Whitney and Merrill Flood at Princeton. A detailed treatment of the connection between Menger and Whitney, and the growth of the TSP as a topic of study, can be found in Alexander Schrijver's paper [32], "On the history of combinatorial optimization (till 1960)" [33].

\subsection{Combinatorial optimization}

The TSP is a problem of discrete or combinatorial optimization. Combinatorial optimization is a branch of optimization in applied mathematics and computer science, related to operations research, algorithm theory and computational complexity theory, 
which sits at the intersection of several fields, including artificial intelligence, mathematics and software engineering.

\subsubsection{Definition of combinatorial optimization}

Many combinatorial problems concern themselves with the choice of a "best" configuration or a set of parameters to achieve certain goals. If this choice can be made from a finite number of possibilities, the problems are called combinatorial optimisation problems. They can be characterized by a configuration space $R$ and a cost function $f$, where $R$ is the set of all configurations and $\mathrm{f}$ assigns to every configuration a quantitative measure with respect to the optimization criteria, in such a way that the lower the value of $f$, the better the corresponding configuration. The optimization objective is to find a configuration that optimizes the cost function; for example, find an $i_{0} \in R$, such that:

$$
f\left(i_{0}\right)=f_{\text {optimal }}=\min \{f(i) \mid i \in R\}
$$

Where $f_{\text {optimal }}$ represents the optimal cost.

The set of optimal configuration is defined as

$$
R_{\text {optimal }}=\left\{i \in R \mid f(i)=f_{\text {optimal }}\right\}
$$

In the TSP, the R denotes a set of the sequence of visited cities in each tour, and the $f$ denotes the cost of each tour. The TSP can be defined as: find $a i_{0} \in R$, such that: 


$$
f\left(i_{0}\right)=\min \{f(i) \mid i \in R\}
$$

\subsubsection{Algorithms and their computational complexity}

To solve the TSP, the most direct solution would be to try all the permutations (ordered combinations) and see which one has the lowest cost. But in an n cities TSP, the number of configurations in the set $R$ is $n !$. When $n$ is larger, the $n$ ! is much larger. Finding the minimum element in an $n$ ! elements space is a task with very high computational complexity. For example, computing at 1 billion times per second, finding the cheapest route in a 100 -city TSP would take more than 350 years. Therefore, the problem of computational complexity has to be considered when applying an algorithm to solve TSP.

Algorithms that solve the combinatorial optimization problem can be classified into two categories, optimal algorithms and approximation algorithms. Optimal algorithms calculate the exact optimum, whereas approximation algorithms calculate the approximate optimum. The optimal algorithm finds the exact optimum, but usually within a prohibitive amount of computing time, whereas an approximation algorithm finds only approximations, but in an acceptable amount of time.

In the TSP, the approximation algorithms can be classified into two categories: local search algorithms and global algorithms. The local search algorithms usually provide a solution using a local optimum. Global algorithms usually provide a global optimization 
solution. For example, the simulated annealing algorithm is a global approximation algorithm.

\subsection{Principle of simulated annealing algorithm}

In 1983, Kirkpatrick [37] proposed a method of using a Metropolis Monte Carlo simulation to find the lowest energy (most stable) orientation of a system. Their method is based upon the procedure used to make the strongest possible glass. This procedure heats the glass to a high temperature so that the glass becomes a liquid and the atoms can move relatively freely. The temperature of the glass is slowly lowered, so that at each temperature the atoms can move enough to begin adopting the most stable orientation. If the glass is cooled slowly enough, the atoms are able to "relax" into the most stable orientation. This slow-cooling process is known as the annealing process, and so their method is called the Simulated Annealing Algorithm.

\subsubsection{Annealing process}

Annealing is a term from thermodynamics: Solids are annealed by raising the temperature to a maximal value at which the particles randomly arrange in the liquid phase, followed by cooling to force the particles into a low-energy state of regular lattice. At each

temperature $\mathrm{T}$, the solid is allowed to reach thermal equilibrium, characterized by a probability distribution of being a state with energy $\mathrm{E}$ given by the Boltzmann distribution: 


$$
P_{r}=\frac{1}{Z(T)} \exp \left(-\frac{E}{k_{B} T}\right)
$$

where $\mathrm{Z}(\mathrm{T})$ is a normalization factor and $\mathrm{k}_{\mathrm{B}}$ the Boltzmann constant. As the temperature decreases, the Boltzmann distribution concentrates on the states with the lowest energy. Finally, when the temperature approaches zero, only minimum energy states have a non-zero probability of occurrence. However, if the cooling is too rapid, the solid is not allowed to reach thermal equilibrium for each temperature value, defects can be "frozen" into the solid and a minimum energy state cannot be reached.

\subsubsection{SA algorithm}

A simulated annealing optimization starts with a Metropolis Monte Carlo simulation at a high temperature. This means that a relatively large percentage of the random steps that result in an increase in energy will be accepted. After a sufficient number of Monte Carlo steps, or attempts, the temperature is decreased. The Metropolis Monte Carlo simulation is then continued. This process is repeated until the final temperature is reached.

\subsubsection{Flow chart of SA algorithm}

A simulated annealing (SA) program consists of a pair of nested DO-loops. The outermost loop sets the temperature, and the innermost loop runs a Metropolis Monte Carlo simulation at that temperature. The way in which the temperature is lowered is known as the cooling schedule. In practice, two different cooling schedules are 
predominantly used: a linear cooling schedule $\left(\mathrm{T}_{\text {new }}=\mathrm{T}_{\text {old }}-\mathrm{dT}\right)$ and a proportional cooling schedule $\left(\mathrm{T}_{\text {new }}=\mathrm{C} \times \mathrm{T}_{\text {old }}\right)$ where $\mathrm{C}<1.0$.

Figure 21 shows the flow chart of the SA algorithm. A simulated annealing optimization starts with an initial solution to the problem, which is also the Best solution so far, and the temperature set at the initial, high temperature Temp (i). This solution becomes the Current solution and the Parent or active solution. The number of Monte Carlo (ITRY) attempts is set to 0 . ITRY is incremented by 1 and is tested to see if it has reached the maximum number of attempts at this temperature. If so, the current temperature is checked. If it is equal to the final temperature, Temp (f), the simulation is finished and both the final solution and the Best solution have been found during the simulation. If the current temperature is above the final temperature, it is reduced using an assigned cooling schedule. If the number of attempts at this temperature has not been reached, or the temperature has been decreased, the Parent solution is modified to generate a new solution. This constitutes the Monte Carlo step. If the energy of the new solution is lower than that of the Parent, it is checked to see if it is the Best solution found. If it is, it is stored separately. Whether or not it is Best, it becomes the new Parent solution for the next Monte Carlo step. Whenever the Parent solution is updated, so is the Current solution. If the energy of the new solution is higher than the Parent's by an amount $d E$, the Boltzmann probability ( $\exp \left(-\frac{d E}{k T}\right)$ where $\mathrm{k}$ is Boltzmann constant and $\mathrm{T}$ is the current temperature) is calculated. If this probability is greater than a random number (Ran) 
between 0.0 and 1.0, this new solution is accepted and becomes the Parent solution for the next iteration, and the Current solution. Conversely, if the Boltzmann probability is less than Ran, the new solution is rejected and the Current/Parent solution stays the same and is used in the next iteration. [38] 


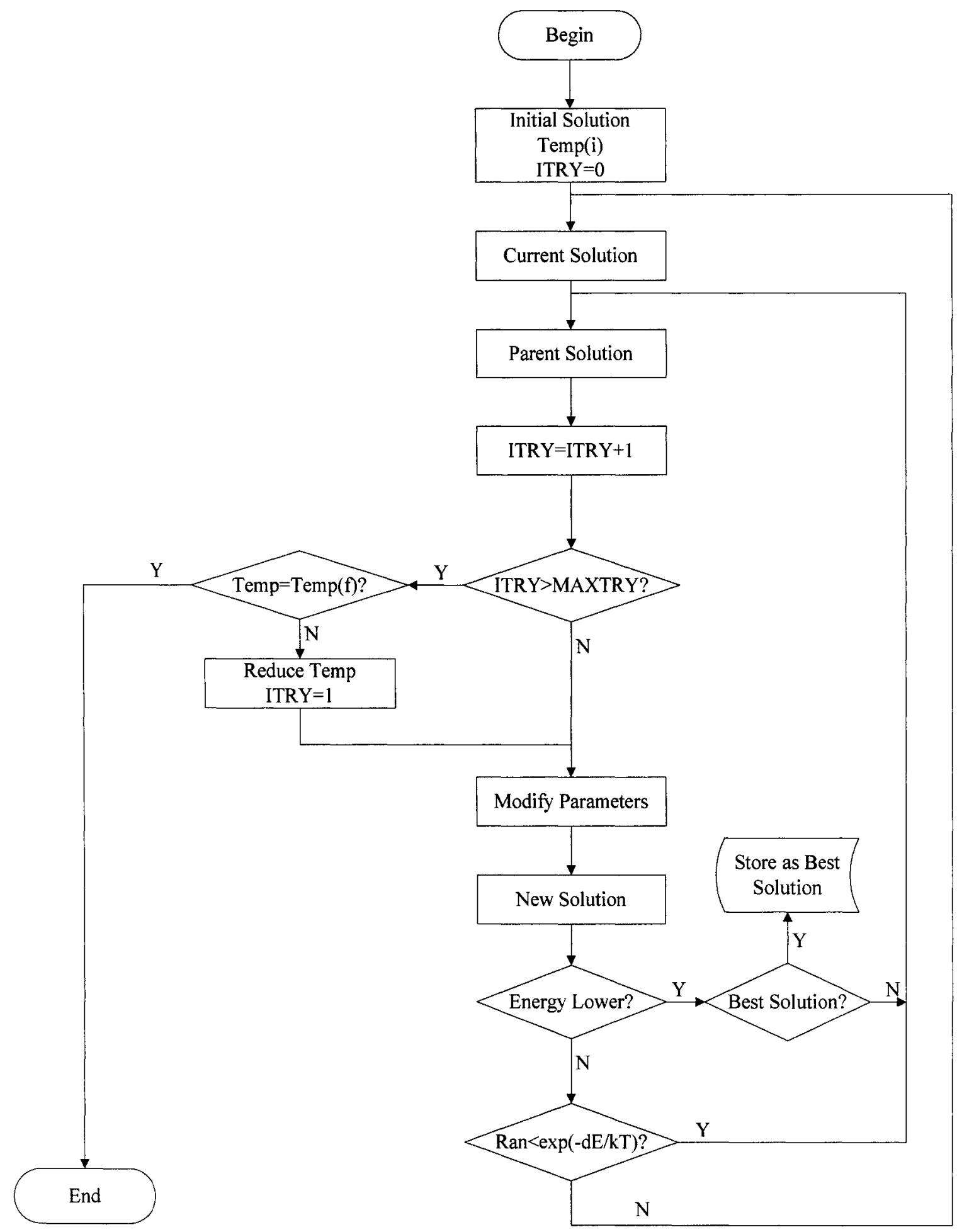

Figure 21: Flow chart of SA algorithm 


\subsection{An example of $\mathrm{SA}$ algorithm in solving the TSP}

We ran an experiment to illustrate how the SA algorithm solves the TSP. In this experiment, we used a MATLAB program developed from the flow chart in Figure 21.

This experiment was run on a DELL Dimension 370 workstation, which included an Intel Pentium 4, 3.6GHZ CPU and 1024Mb RAM. The operating system was Microsoft Windows XP. The program was implemented in MATLAB 7.0. To illustrate the SA algorithm convergence speed, we recorded the total route length and the computation time at different temperature levels in an annealing process.

First, we randomly generated 100 cities in a 1,000 $\mathrm{km}^{2}$ area, shown in Figure 22. Second, we defined the cost function $\mathrm{f}$, which is the total length of a tour. The tour route visited all cities only once and came back to the starting city. 


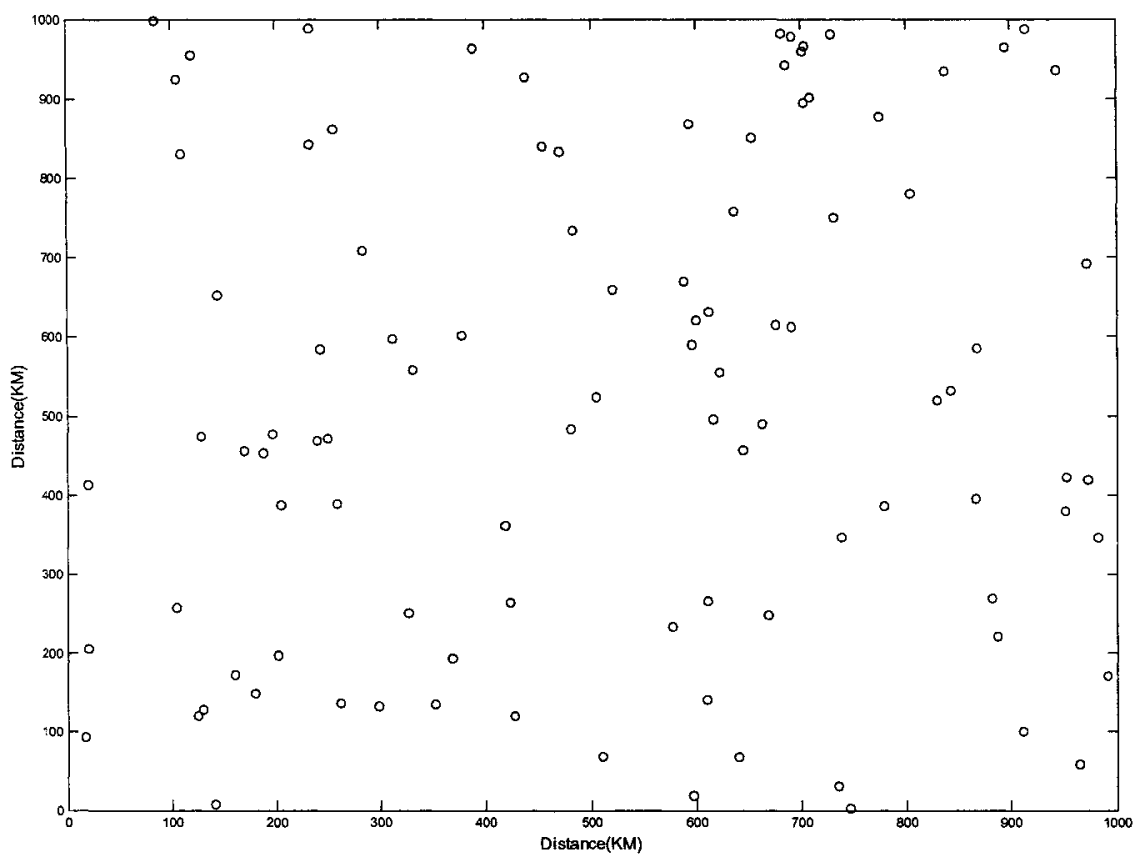

Figure 22: 100 cities in a $1,000 \mathrm{~km}^{2}$ area

We preset the initial temperature parameter at 1000 and the freezing temperature as 0.001 . We applied a proportional cooling schedule $\left(\mathrm{T}_{\text {new }}=\mathrm{C} \times \mathrm{T}_{\text {old }}\right)$ where $\mathrm{C}=0.87$. These parameters are chosen from a fastest simulation in a several simulations whose parameters are preset by different values.

Figure 23 shows the initial tour route of 100 cities, whose cost function $\mathrm{f}$ was very high. 


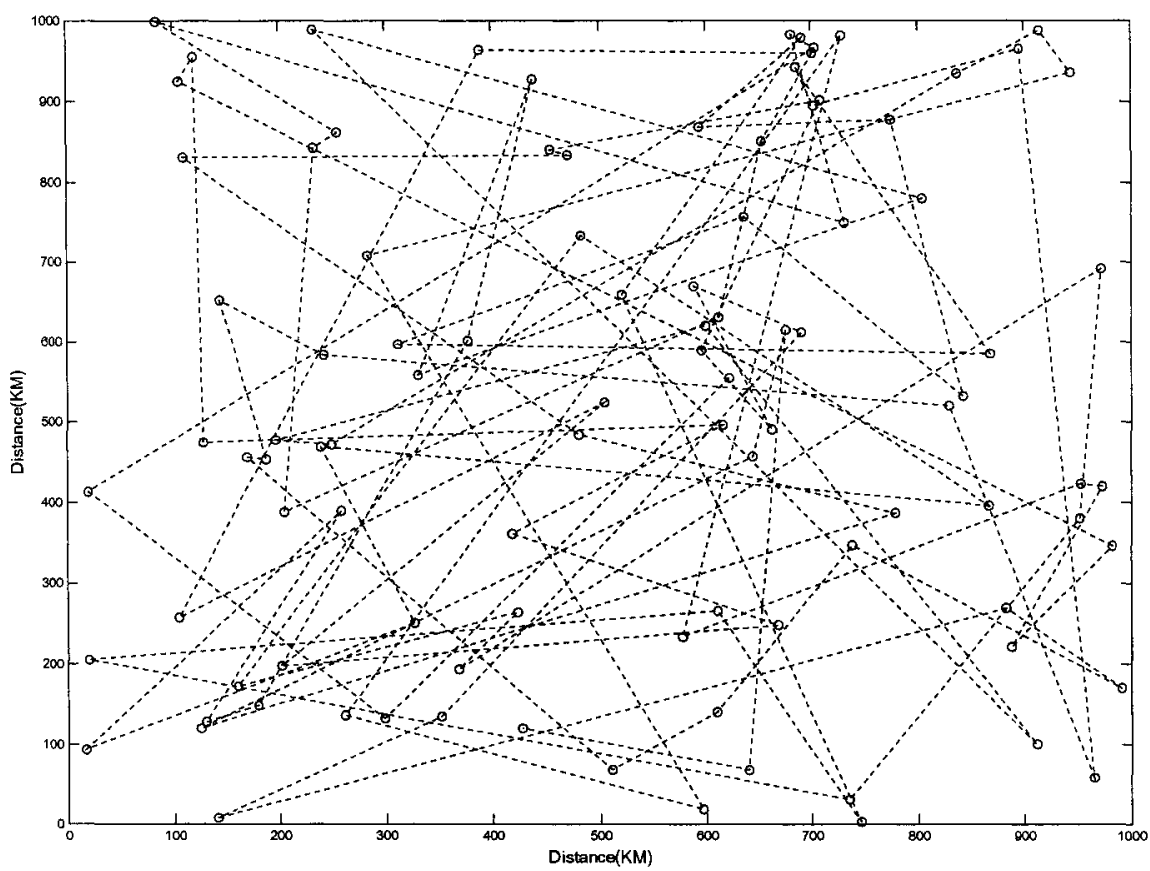

Figure 23: Temperature parameter $=1000$

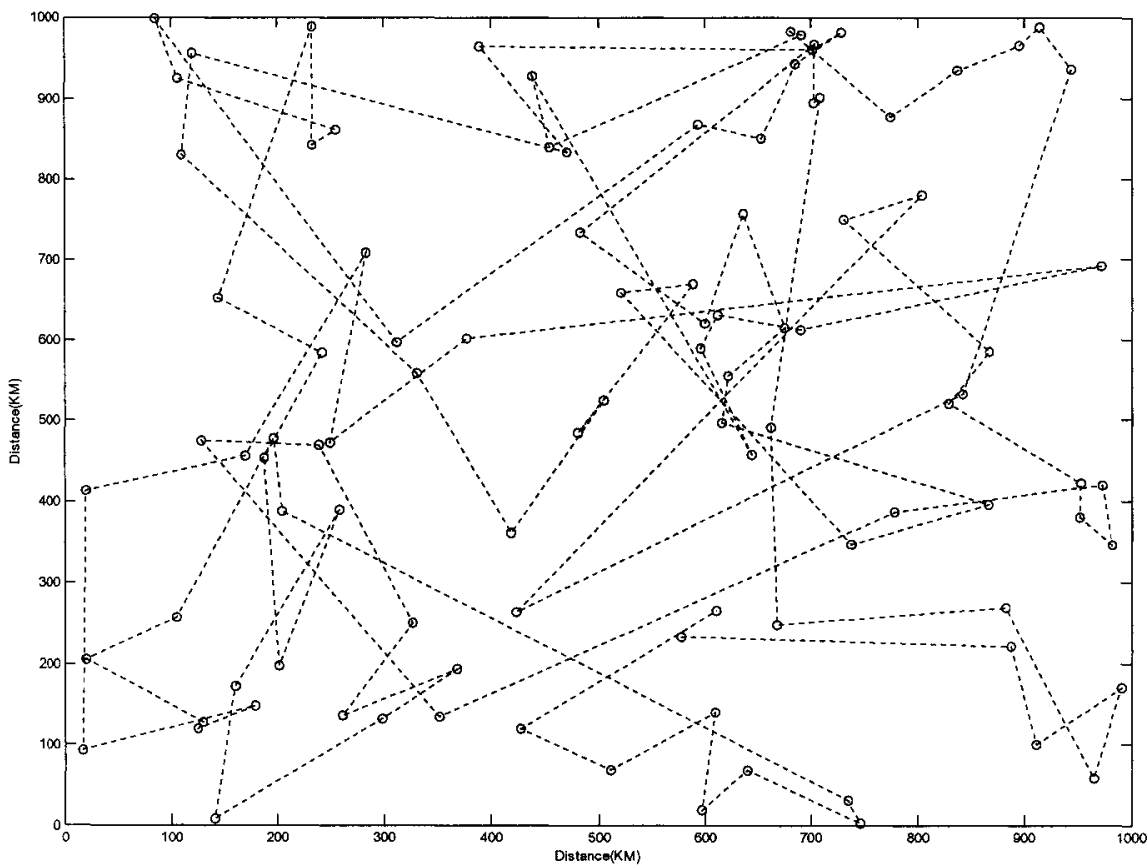

Figure 24: Temperature parameter $=188$ 


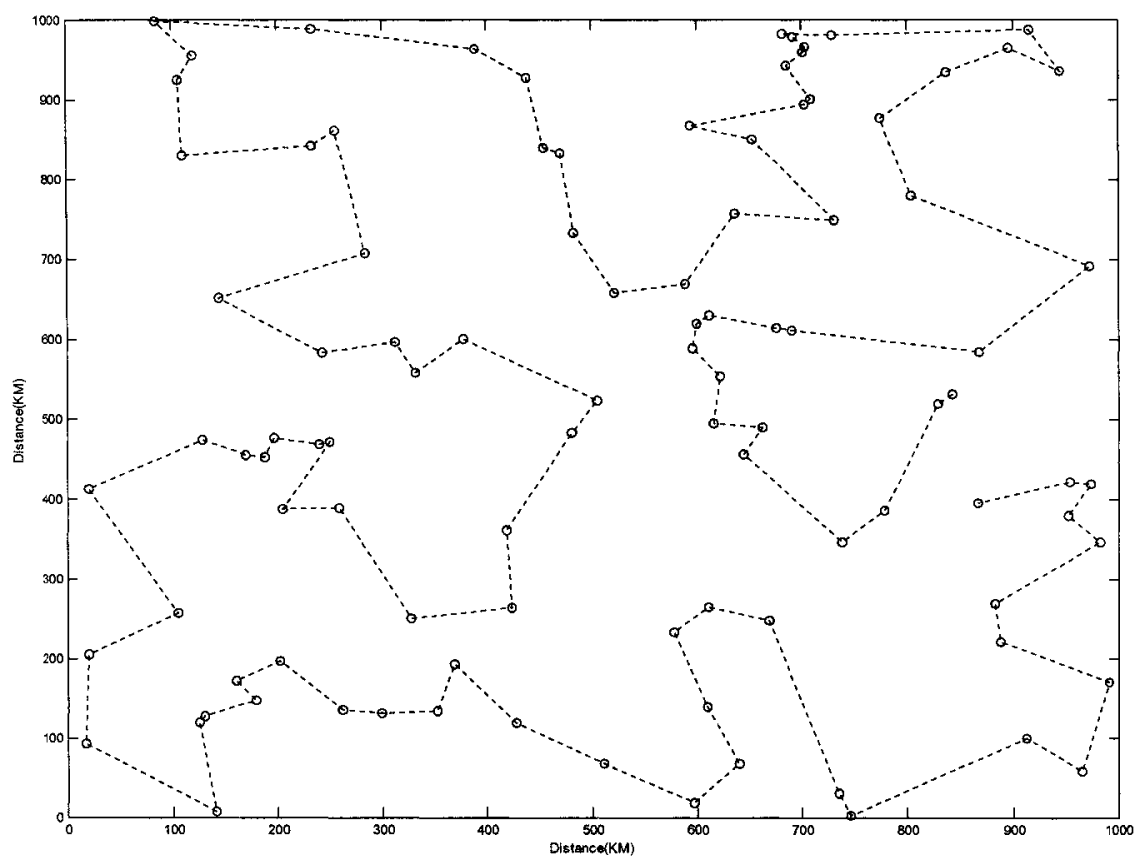

Figure 25: Temperature parameter $=\mathbf{1 0 . 1}$

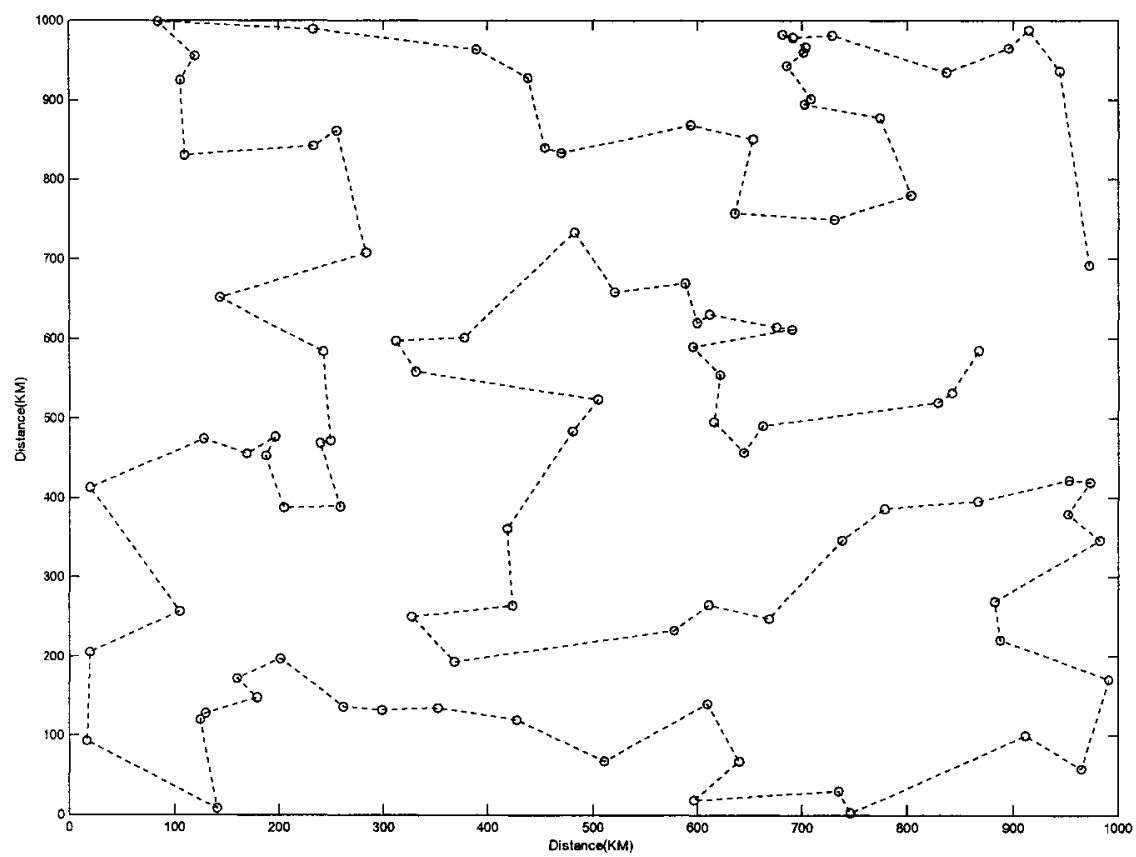

Figure 26: Temperature parameter $=\mathbf{0 . 0 0 1}$ 
When the temperature parameter decreased to 188 , the SA program outputs an improved tour route, which is shown in Figure 24. The cost f, which represents the total tour route length, reduces greatly.

When the temperature parameter decreased to 10.1 , we obtained a non-cross tour route, which is shown in Figure 25. The total route length was reduced to a near-optimal level.

When the temperature parameter reached the freezing point, preset at 0.001 , we got the output shown in Figure 26.

Table 2 and Figure 27show the results of the experiment.

Table 2: Total length and computation time

\begin{tabular}{|c|c|c|c|c|}
\hline $\begin{array}{c}\text { Temperature } \\
\text { Parameter }\end{array}$ & 1000 & 188 & 10.1 & 0.001 \\
\hline $\begin{array}{c}\text { Total length } \\
\text { (KM) }\end{array}$ & 43403 & 18683.8 & 8154.3 & 8019.4 \\
\hline $\begin{array}{c}\text { Computation } \\
\text { time (SEC) }\end{array}$ & 0.51585 & 6.1703 & 9.5266 & 48.61 \\
\hline
\end{tabular}

As shown in Table 2 and Figure 27, the SA algorithm resulted in a near-optimal route within 10 seconds when the temperature parameter was reduced to 10.1 . Reaching the freezing temperature, 0.001 , cost almost $500 \%$ time and only reduces $1 \%$ of the total length. 


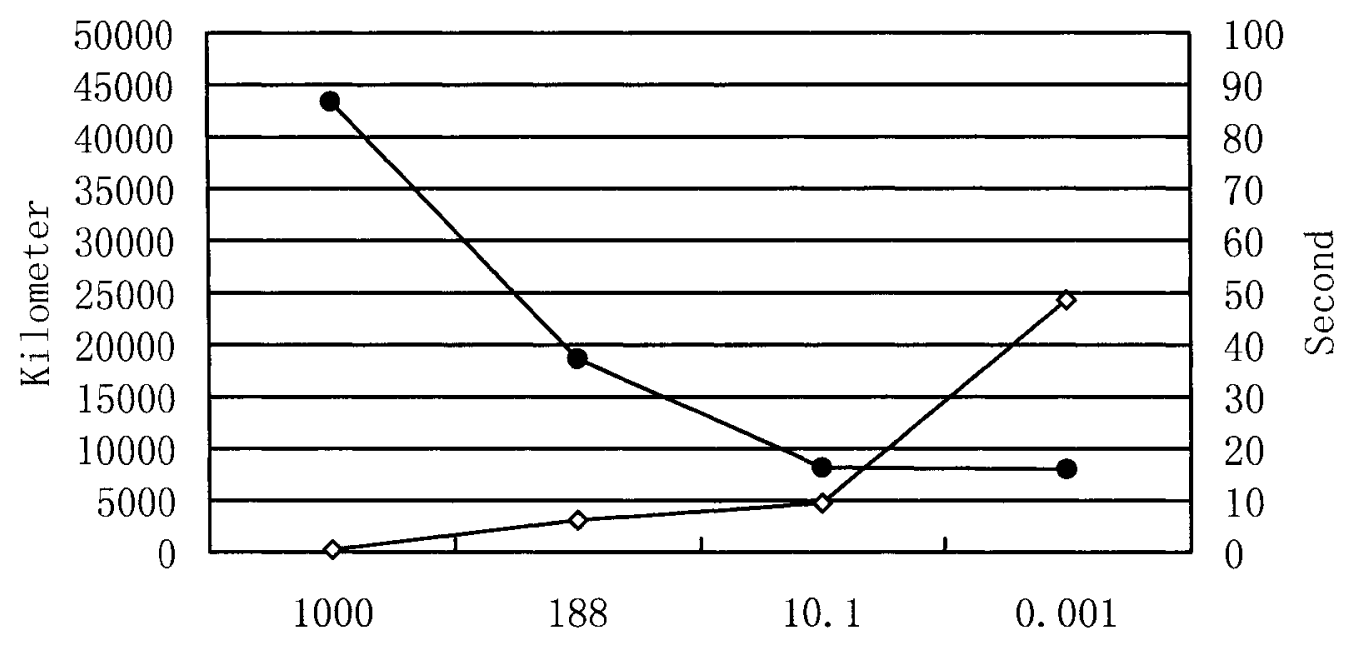

Temperature parameter

$\rightarrow$ Total length $\leadsto$ Computation time

Figure 27: Total length and computation time

To find the absolutely shortest route in this TSP, the optimal algorithms will take years on this PC and the absolutely shortest route is only $2-3 \%$ shorter than the approximately optimal route that was obtained by the SA algorithm. Therefore, the SA algorithm is more applicable in practice.

Compared with the greedy algorithm, which is a local search, the SA algorithm calculates the cost function $f$ at each annealing stage. The cost function is calculated from the global information. Therefore, the SA algorithm can provide an approximate global optimal route that is better than the route calculated from the greedy algorithm, and the computation time is acceptable. 


\subsection{Application of SA algorithm in WSNs}

From the theoretical proof, a new chain-based protocol that incorporates the SA algorithm can provide better performance than the PEGASIS. Therefore, we have developed a chain-based protocol called the SA chain protocol.

In the SA chain protocol, the sensor nodes apply the TDMA MAC protocol to collect data within the chain, and finally send the data to the base station.

This protocol has four phases.

\subsubsection{Pre-setup phase}

In this phase, the base station broadcasts the wakeup time to all the sensor nodes. When the sensor nodes detect the wakeup signal, they broadcast their sensor node ID at maximum transmission power, $\mathrm{P}_{\mathrm{t}-\mathrm{max}}$. When all sensor nodes have completed the broadcasting step, every sensor node and the base station receive all the sensor nodes' signals and their IDs. Each sensor node and the base station record the receiving signal power of the other sensor nodes with their ID, $\mathrm{P}_{\mathrm{r}} . \mathrm{P}_{\mathrm{r}} / \mathrm{P}_{\mathrm{t}-\mathrm{max}}$ denotes the cost of transmission between sensor nodes. Every sensor node transmits the information of each $\mathrm{P}_{\mathrm{r}}$ with ID directly to the base station. Thus, in this phase, the base station will have a cost matrix that includes the cost information of all the sensor nodes. 


\subsubsection{Chain set-up phase}

From the cost matrix that was drawn up in the pre-setup phase, the base station runs the SA program, which is developed from the flow chart in Figure 21. The base station forms a closed chain, which provides an approximately optimal cost. The base station randomly assigns a chain leader in the first round; the chain member that is next to the chain leader will be the chain leader in the next round. The chain routing table and the ID of the chain leader will be broadcast to all the sensor nodes by the base station.

Figure 28 shows the SA chain and a chain leader in a WSN.

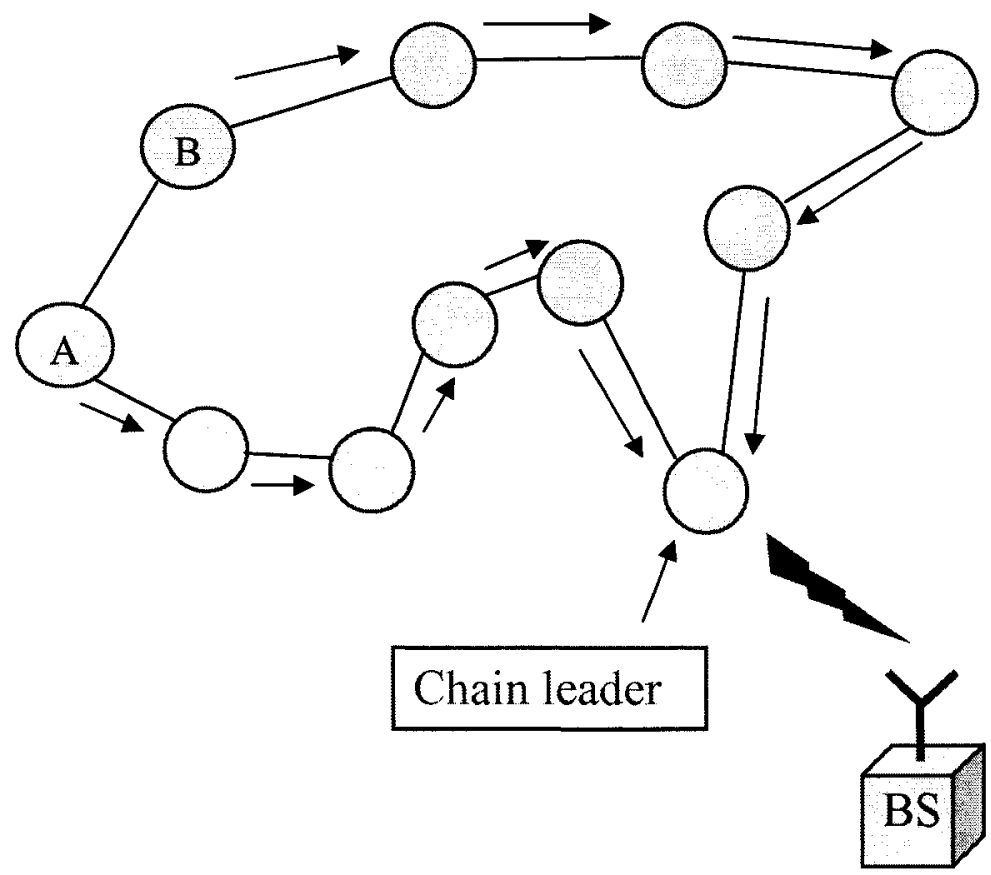

Figure 28: SA chain and the chain leader 


\subsubsection{Data-gathering phase}

In the data-gathering phase, all the sensor nodes receive the chain routing table and the ID of the chain leader. If a sensor node finds it is the chain leader, it will wait to receive the information packets from all the chain members. At the end of a data-gathering round, the chain leader fuses the received information packets and sends them to the base station. If the chain leader does not receive information packets from all the chain members, it will report the ID of the absent chain member to the base station.

If a sensor node finds it is a chain member, it will calculate the routing distance to the chain leader. If it is one of the two farthest chain members, it will be the first information packet sender in the data-gathering phase. Otherwise, it will wait for the information packet from the sensor nodes that are farther on the routing table. The first sender chooses the direction that is nearest to the chain leader, clockwise or anti-clockwise. Then it sends a fused information packet, which includes information from its sensor and the received packet, to the next sensor node on the routing table. Figure $\mathbf{2 8}$ shows sensor nodes A and B as the two sensor nodes farthest from the chain leader. Sensor node B chooses the clockwise direction, which is five hops from the chain leader, and sensor node A chooses the other direction.

When a sensor node receives an information packet, the receiver will reply with a short packet back to the sender. If a sender does not receive a reply packet, the sender 
considers the receiver to be dead. The sender will skip the dead sensor on the routing table and send the information packet to the next sensor node.

If the chain leader is dead, the entire information packet will be saved in each sensor node's storage and be sent out on the next data-gathering round.

\subsubsection{Reconfiguration phase}

During the data-gathering phase, the base station records the IDs of any absent chain members. If a sensor node is found to be absent during a data-gathering round, the base station will delete it in the chain routing table and broadcast the new chain routing table to all sensor nodes. In the next data-gathering round, the sensor nodes will send the information packets according to the new routing table. If a chain leader is found to be dead, the next nearest sensor node will be chosen as the new chain leader in the next round.

When $10 \%$ of the sensor nodes are found to be dead in the WSN, the base station will move into the chain set-up phase and calculate a new SA chain. 


\section{SIMULATION AND DISCUSSION}

This chapter illustrates and discusses our simulation of the direct transmission protocol, the PEGASIS protocol and the SA chain protocol in three WSNs of different scales. The performance of these protocols is clearly presented in all aspects through these detailed simulations and experiments. 


\subsection{Simulation environment and assumptions}

The experiments were carried out on a DELL Precision 370 workstation that included an Intel Pentium 4 3.6GHZ CPU and 1024Mb RAM. The operating system was Microsoft Windows XP. The program was implemented in MATLAB 7.0.

As illustrated in Table 1, the direct transmission protocol and the PEGASIS protocol have different advantages in WSNs of different scales. We therefore simulated the direct transmission protocol, PEGASIS protocol, and SA chain protocol in three WSNs of different scales. We define a small-scale WSN as having 10 sensor nodes in a $10 \mathrm{X} 10 \mathrm{~m}^{2}$ sensor field, a medium-scale WSN as 100 sensor nodes in a $50 \times 50 \mathrm{~m}^{2}$ sensor field, and a large-scale WSN as 1,000 sensor nodes in $300 \times 300 \mathrm{~m}^{2}$.

In these three WSNs, we simulated the base station separately, outside the sensor field and inside the sensor field. In the outside simulation, the distance between the base station and the sensor field was twice the length of the side. In the inside simulation, the base station was in the centre of the sensor field.

In all experiments, we assumed all the sensor nodes and the base station were on a flat plane and there were no obstacles between the sensor nodes and the base station. Each sensor node could communicate with the base station directly. 
To make a fair comparison with PEGASIS, in the medium-sized WSN experiments, we used the same size of sensor field and the same sensor node positions and base station position that were used in Lindsey's simulation.

\subsection{Energy model}

\subsubsection{Wireless propagation model}

For the wireless channel propagation, we adopted the free space model. The free space model equation is as follows:

$$
P_{r}=\frac{P_{t} G_{t} G_{r} \lambda^{2}}{(4 \pi d)^{2}}
$$

where $P_{r}$ is the receive power; $P_{t}$ is the transmission power; $G_{t}$ and $G_{r}$ are the gains of the transmitting and receiving antenna respectively; $\lambda$ is the wavelength of the carrier signal; $\mathrm{d}$ is the distance between transmitter and receiver.

From equation (6.1), we get

$$
P_{t}=\frac{P_{r}(4 \pi d)^{2}}{G_{t} G_{r} \lambda^{2}}
$$

To ensure sensor nodes can receive the wireless signal correctly, the $P_{r}$ must satisfy a

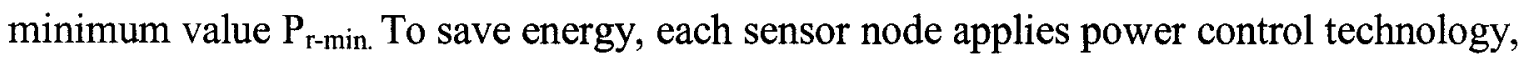
which controls the $\mathrm{P}_{\mathrm{t}}$ and maintains $\mathrm{P}_{\mathrm{r}}$ at the minimum level. 
Therefore, we obtain the minimum wireless transmission power $\mathrm{P}_{\mathrm{t}-\mathrm{min}}$ in equation (6.3)

$$
P_{t-\min }=\frac{P_{r-\min }(4 \pi d)^{2}}{G_{t} G_{r} \lambda^{2}}
$$

Assuming $P_{r-\min }, G_{t}, G_{r}$, and $\lambda$ are constants as specifications of each sensor, we define a constant $\mathrm{k}$

$$
k=16 \frac{\pi^{2}}{G_{t} G_{r} \lambda^{2}} P_{r-\min }
$$

Then, we get the $\mathrm{P}_{\mathrm{t}-\mathrm{min}}$ as a function of $\mathrm{d}$.

$$
P_{t-\min }=k \cdot d^{2}
$$

\subsubsection{Energy consumption model}

In wireless data communication, each sensor node consumes a hundred times more energy when transmitting data than when receiving and processing data. Therefore, we assume the energy used for transmission is all the consumed energy. We define the energy consumption for transmitting one information packet as E. We get equation (6.6):

$$
E_{\text {sensor }}=a \cdot k \cdot d^{2}
$$

where $\mathrm{a}$ is the parameter regards to time

We define the $b$ :

$$
\begin{gathered}
b=a \cdot k \\
E_{\text {sensor }}=b \cdot d^{2}
\end{gathered}
$$


Then, we get all the network energy consumption in one data-gathering round:

$$
E_{\text {network }}=\sum_{i=1}^{n} E_{i}
$$

where $E_{\text {network }}$ denotes network energy consumption and $E_{i}$ denotes the $i$-th sensor node's energy consumption in one data-gathering round.

In the direct transmission protocol, the $\mathrm{E}_{\text {network }}$ is

$$
E_{n e t w o r k}=\sum_{i=1}^{n} b \cdot\left(d_{i \sim b a s e}\right)^{2}
$$

where $d_{i \sim \text { base }}$ denotes the distance from the $i$-th sensor nodes to the base station

In the PEGASIS protocol, the $\mathrm{E}_{\text {network }}$ is

$$
E_{\text {network }}=\sum_{i=1}^{m-1} b \cdot\left(d_{i \sim i+1}\right)^{2}+b \cdot\left(d_{m \sim b a s e}\right)^{2}+\sum_{i=m+1}^{n} b \cdot\left(d_{i-1 \sim i}\right)^{2}
$$

where $d_{i-1 \sim i}$ denotes the distance of the (i-1)-th sensor nodes to the $\mathrm{i}$-th sensor node in the greedy chain, and $d_{m}$ base denotes the distance from the $m$-th sensor nodes, which is the chain leader to the base station.

In the $\mathrm{SA}$ chain protocol, when $\mathrm{n}$ is even, the $\mathrm{E}_{\text {network }}$ is

$$
E_{\text {network }}=\sum_{i=1}^{n / 2-1} b \cdot\left(d_{i \sim i+1}\right)^{2}+b \cdot\left(d_{n / 2 \sim b a s e}\right)^{2}+\sum_{i=n / 2+1}^{n} b \cdot\left(d_{i-1 \sim i}\right)^{2}
$$


When $\mathrm{n}$ is odd, the $\mathrm{E}_{\text {network }}$ is

$$
E_{\text {network }}=\sum_{i=1}^{(n-1) / 2} b \cdot\left(d_{i \sim i+1}\right)^{2}+b \cdot\left(d_{(n+1) / 2 \sim \text { base }}\right)^{2}+\sum_{i=(n+3) / 2}^{n} b \cdot\left(d_{i-1 \sim i}\right)^{2}
$$

where $d_{i-i+1}$ denotes the distance of the (i-1)-th sensor nodes to the $i$-th sensor node in the SA chain, and $d_{n / 2 \text { base }}$ or $d_{(n+1) / 2 \text { base }}$ denotes the distance from the $n / 2$-th or $(n+1) / 2$-th sensor nodes, which is the chain head to the base station.

To minimize the $E_{\text {network }}$ by $S A$ algorithm, we define the cost function as $E_{\text {network }}$ and try to find an approximate lowest energy consumption route.

\subsection{Small-scale WSN with 10 sensor nodes}

To compare protocols in a small-scale WSN, we random deployed 10 sensor nodes in a $10 \times 10 \mathrm{~m}^{2}$ area.

\subsubsection{Chain structure comparison}

Figure 29 shows the greedy chain structure of the PEGASIS protocol. Figure 30 shows the SA chain structure. 


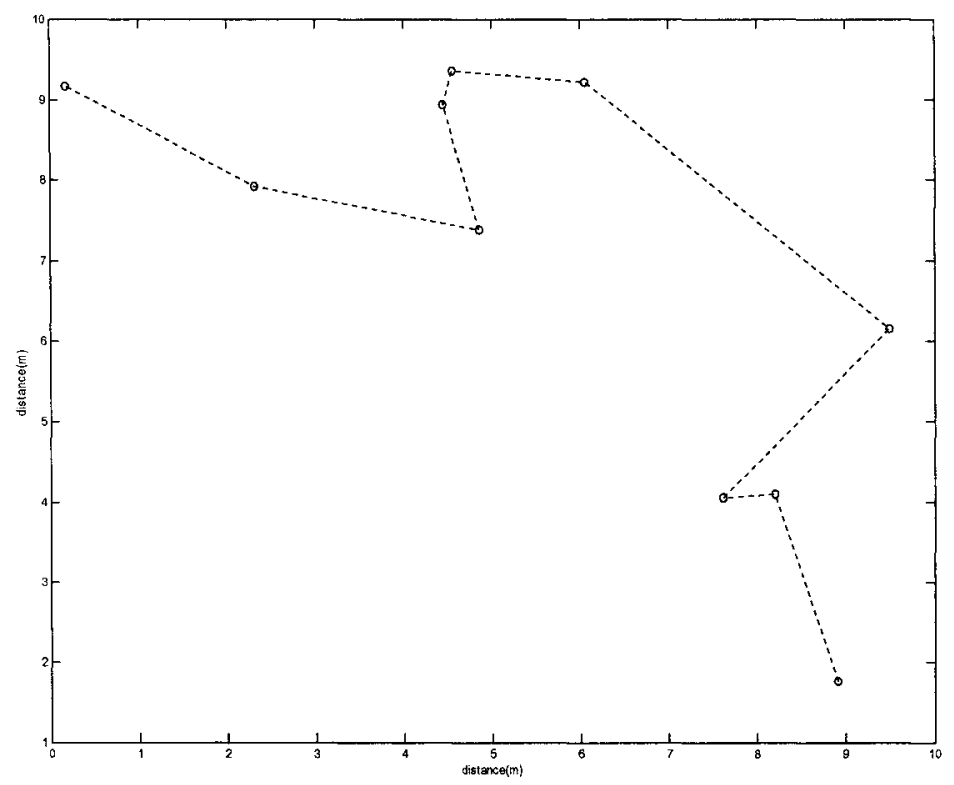

Figure 29: 10 nodes, greedy chain

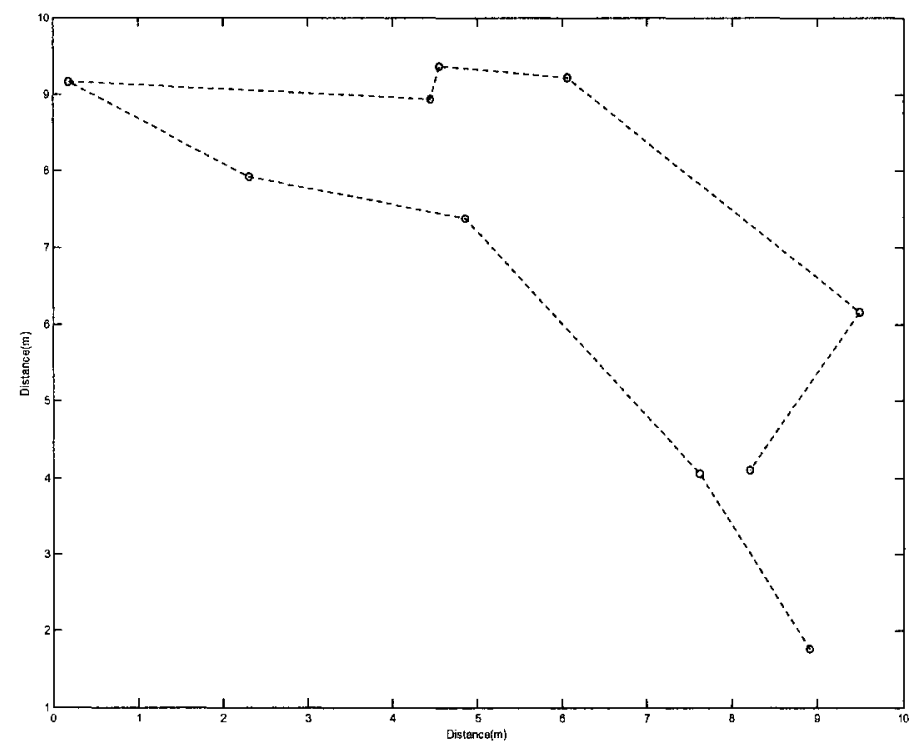

Figure 30: 10 nodes, SA chain 


\subsubsection{Energy efficiency and computation time comparison}

From the energy model, we calculated the energy consumption in 10 data-gathering rounds. We also recorded the computation time of each algorithm. The result is shown in Table 3.

Table 3: Energy efficiency and computation time comparison in a 10-node WSN

\begin{tabular}{|c|c|c|c|}
\hline $\begin{array}{c}\text { Base station } \\
\text { position }\end{array}$ & Direct & PEGASIS & SA chain \\
\hline $\begin{array}{c}(5,5) \\
\text { Inside sensor field } \\
\text { (Energy unit=b) }\end{array}$ & 1821.8 & 201.3 & 149.1 \\
\hline $\begin{array}{c}(5,15) \\
\text { Outside sensor field } \\
\text { (Energy unit=b) }\end{array}$ & 8210.5 & 840.1 & 412.7 \\
\hline $\begin{array}{c}\text { Computation time } \\
\text { (Second) }\end{array}$ & 0 & 0.001 & 3.006 \\
\hline
\end{tabular}

From Table 3, we plotted Figure 31. The simulations, which included the base station both inside and outside the sensor field, showed that the PEGASIS protocol consumed twice energy as the SA chain. The direct communication protocol had 10 times the energy consumption of the PEGASIS and 15-20 times that of the SA chain protocol.

The computation time of the direct communication protocol was zero, because the direct communication protocol did not calculate the routing table. The computation time of the PEGASIS protocol was almost zero. The SA chain protocol cost three seconds to compute. 


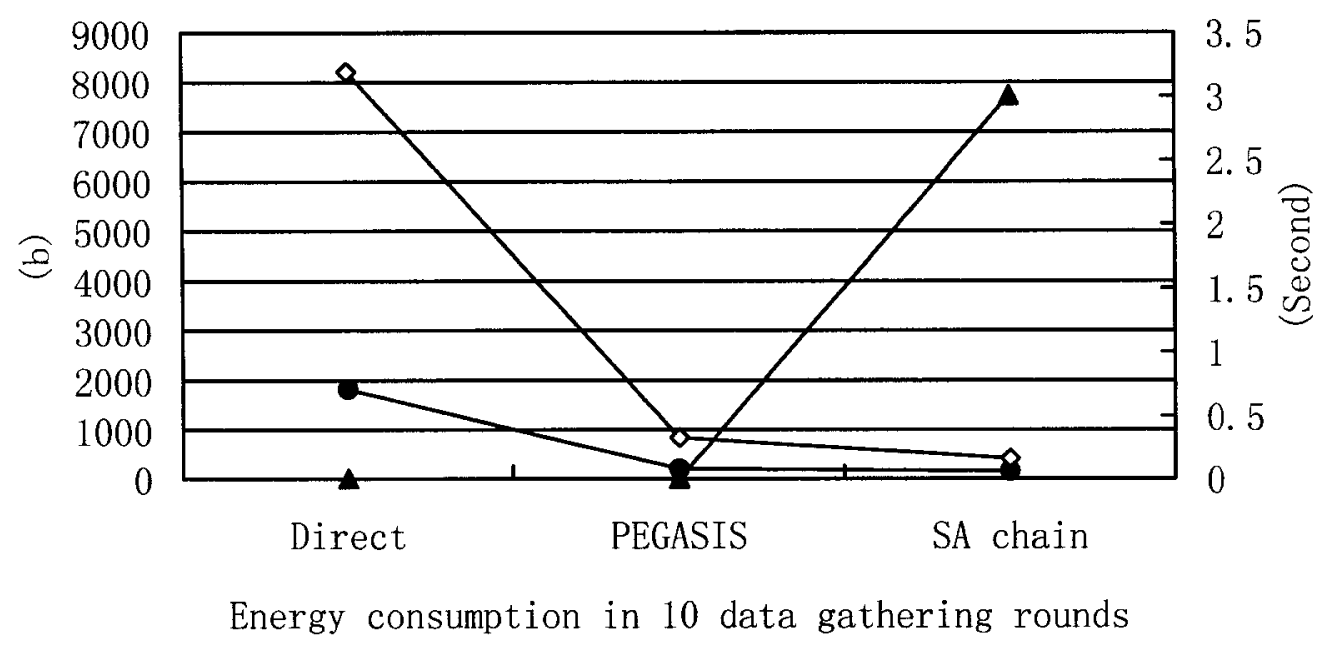

Inside sensor field $\diamond$ outside sensor field $\rightarrow$ Computation time

Figure 31: Energy efficiency and computation time comparison in a 10-node WSN

\subsubsection{Lifetime comparison}

Given $1000 \mathrm{~b}, 5000 \mathrm{~b}$, and $10000 \mathrm{~b}$ units of energy for each sensor node respectively, the WSN's average lifetime is shown in Table 4. When the base station is inside the sensor field, the lifetime of the SA chain protocol is 12 times longer than the direct transmission protocol, and that of the PEGASIS protocol 7 times longer than the direct transmission protocol. When the base station is outside the sensor field, the lifetime of the SA chain protocol is 20 times longer than the direct transmission protocol, and the PEGASIS protocol has a lifetime 10 times longer than the direct transmission protocol. 
Table 4: Lifetime comparison in a 10-node WSN

\begin{tabular}{|c|c|c|c|c|}
\hline \multirow{2}{*}{$\begin{array}{c}\text { Base station } \\
\text { position }\end{array}$} & $\begin{array}{c}\text { Initial } \\
\text { sensor node } \\
\text { energy }\end{array}$ & Direct & PEGASIS & SA chain \\
\hline $\begin{array}{c}\text { inside sensor field } \\
\text { (lifetime unit=round) }\end{array}$ & $1000 \mathrm{~b}$ & 54 & 425 & 670 \\
\cline { 2 - 5 } & $10000 \mathrm{~b}$ & 548 & 4968 & 6707 \\
\hline \multirow{2}{*}{$\begin{array}{c}(5,15) \\
\text { outside sensor field } \\
\text { (lifetime unit=round) }\end{array}$} & $5000 \mathrm{~b}$ & 274 & 2484 & 3353 \\
\cline { 2 - 5 } & $1000 \mathrm{~b}$ & 12 & 119 & 242 \\
\cline { 2 - 5 } & $10000 \mathrm{~b}$ & 121 & 1191 & 2422 \\
\hline
\end{tabular}

\subsection{Medium-scale WSN with 100 sensor nodes}

To draw a fair comparison with the PEGASIS protocol, in the medium-scale WSN we used position data that included the base station and sensor node positions from Lindsey's simulation.

\subsubsection{Chain structure comparison}

Figure 32 and Figure 33 show the structure of the greedy chain and the SA chain. The greedy chain has some crosses, while the SA chain has none. 


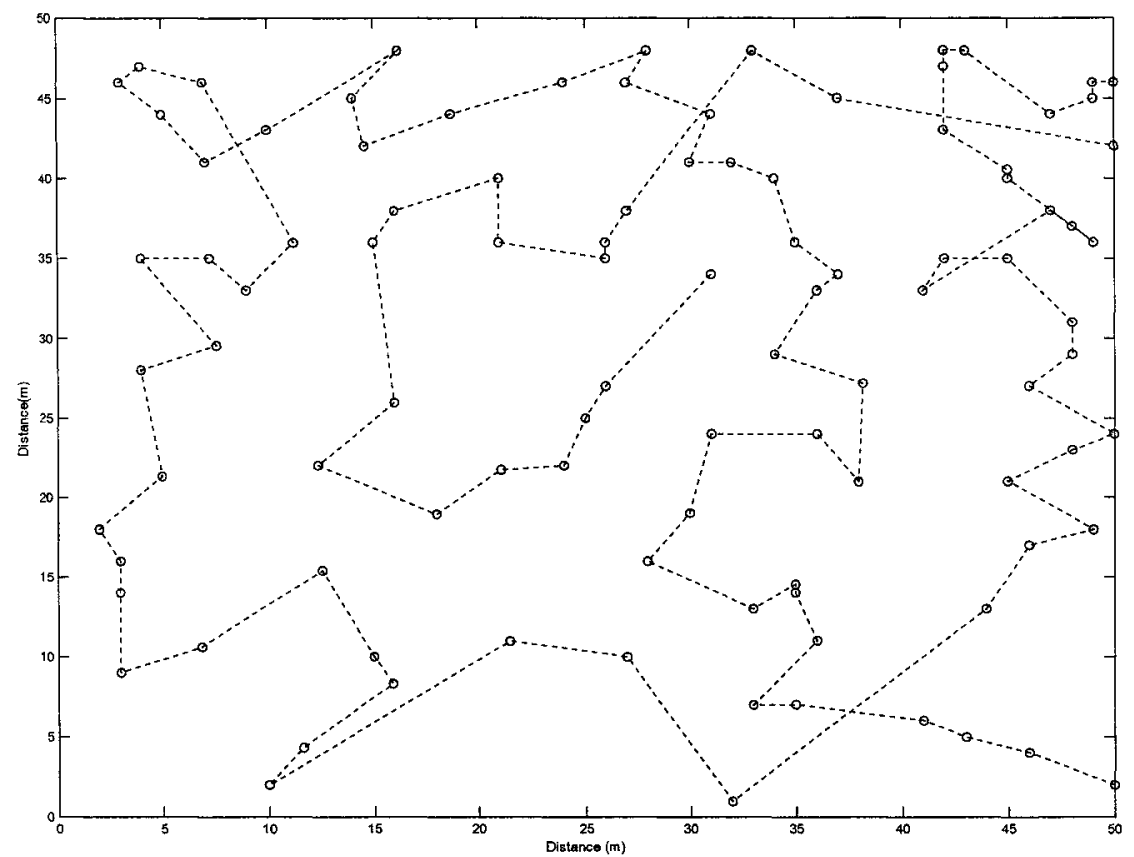

Figure 32: 100-node, Greedy chain

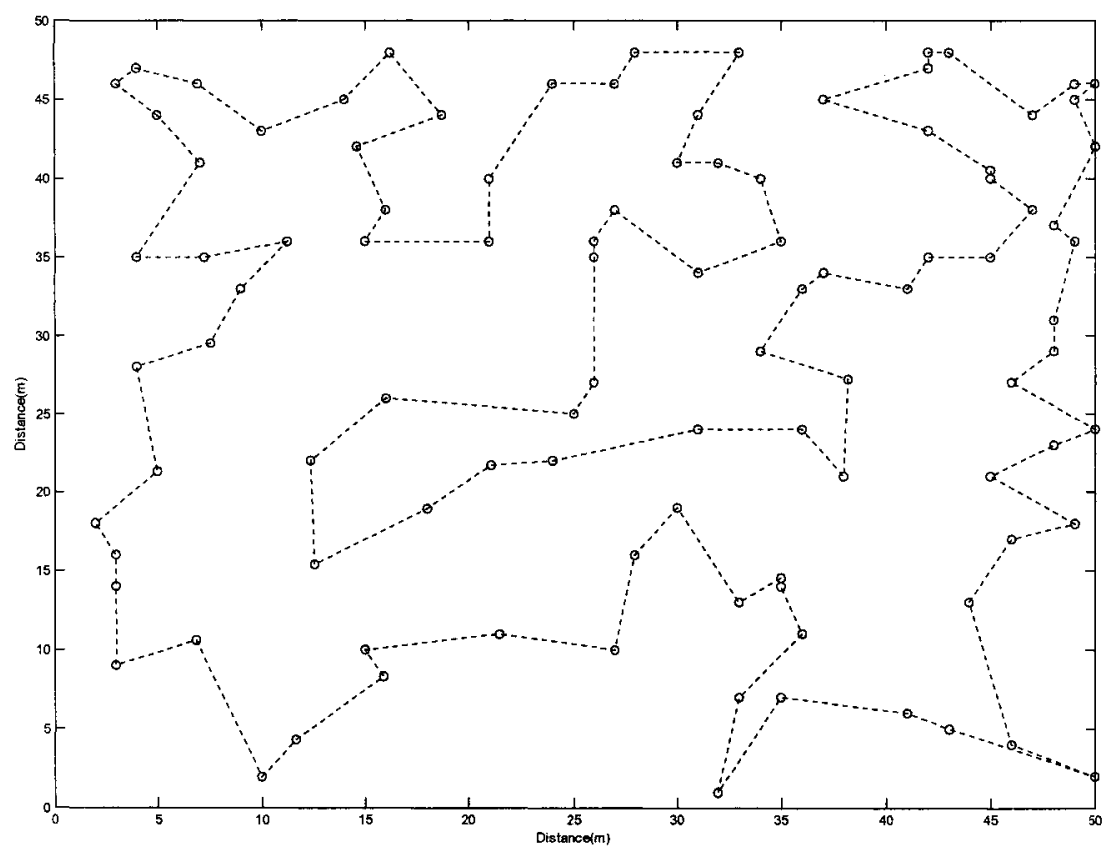

Figure 33: 100-node, SA chain 


\subsubsection{Energy efficiency comparison}

From the energy model, we were able to calculate the energy consumption in 100 data-gathering rounds. We also recorded the computation time of each algorithm. The results are shown in Table 5.

Table 5: Energy efficiency and computation time comparison in a 100-node WSN

\begin{tabular}{|c|c|c|c|}
\hline $\begin{array}{c}\text { Base station } \\
\text { position }\end{array}$ & Direct & PEGASIS & SA chain \\
\hline $\begin{array}{c}(25,25) \\
\text { Inside of sensor field } \\
\text { (Energy unit=b) }\end{array}$ & 4485869 & 47447 & 21560 \\
\hline $\begin{array}{c}\text { Outside of sensor field } \\
\text { (Energy unit=b) }\end{array}$ & 150705869 & 1509632.13 & 1043375 \\
\hline $\begin{array}{c}\text { Computation time } \\
\text { (Second) }\end{array}$ & 0 & 0.01 & 16.6 \\
\hline
\end{tabular}

Table 5 shows that the PEGASIS protocol consumes twice energy as the SA chain protocol when the base station is inside the sensor field, and 1.5 times as much as the SA chain protocol when the base station is outside the sensor field. The direct communication protocol consumes 10 to 20 times more energy than the PEGASIS and SA chain protocols.

Figure 34 shows the comparison between the PEGASIS protocol and the SA chain protocol. The SA chain protocol consumed only $50 \%$ to $70 \%$ of the energy consumed by 
the PEGASIS protocol, while the SA chain protocol cost 16.6 seconds more time in the pre-setup phase.

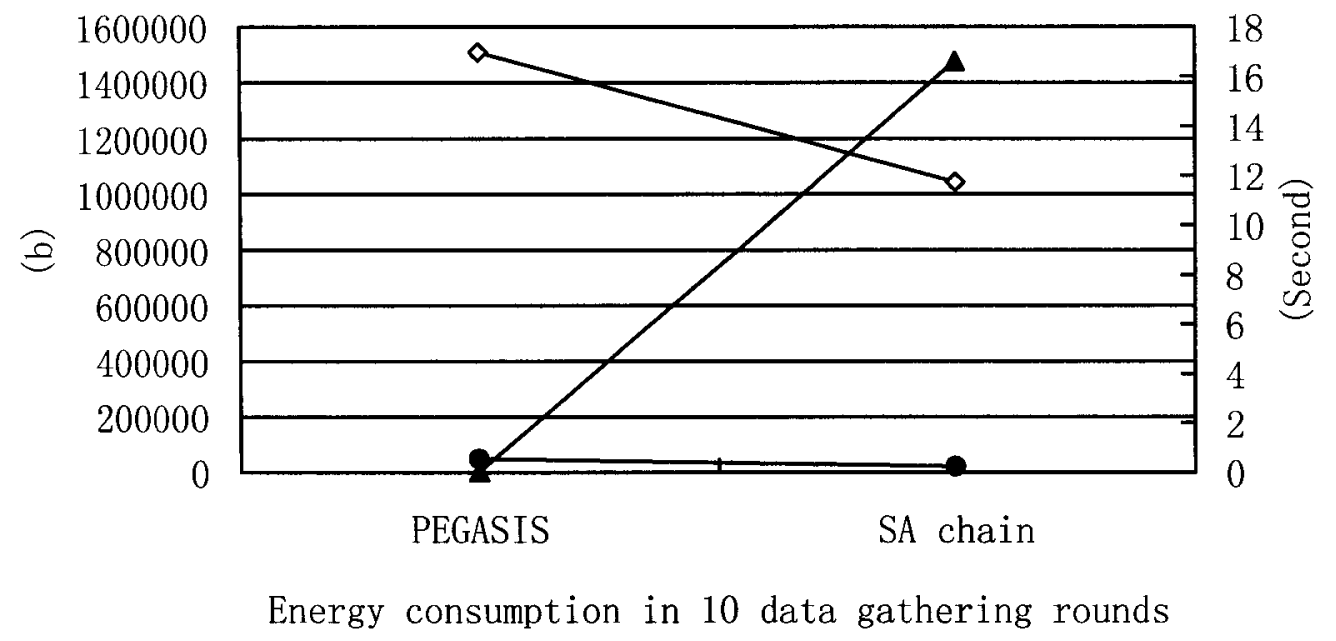

Inside sensor field $\leadsto$ outside sensor field $\rightarrow$ Computation time

Figure 34: Energy efficiency and computation time comparison in a 100-node WSN

\subsubsection{Lifetime comparison}

Given $1 \times 10^{5} \mathrm{~b}, 5 \times 10^{5} \mathrm{~b}$, and $1 \times 10^{6} \mathrm{~b}$ units of energy for each sensor node respectively, the average lifetime is shown in Table 6. When the base station is inside the sensor field, the SA chain protocol has a lifetime 2.5 times longer than the PEGASIS. When the base station is outside the sensor field, the SA chain protocol has a lifetime 1.5 times longer than the PEGASIS protocol. The lifetime of the SA chain protocol is 24 times longer than the direct transmission protocol when the base station is inside the sensor field. The lifetime of the PEGASIS protocol is 100 times longer than the direct transmission 
protocol when the base station is inside the sensor field. This result coincides with Lindsey's simulation result.

Table 6: Lifetime comparison in a 100-node WSN

\begin{tabular}{|c|c|c|c|c|}
\hline $\begin{array}{l}\text { Base station } \\
\text { position }\end{array}$ & $\begin{array}{c}\text { Initial } \\
\text { sensor node } \\
\text { energy }\end{array}$ & Direct & PEGASIS & SA chain \\
\hline \multirow{3}{*}{$\begin{array}{l}(25,25) \\
\text { inside of sensor field } \\
\text { (Lifetime unit=round) }\end{array}$} & $10000 \mathrm{~b}$ & 8 & 2108 & 4819 \\
\hline & $50000 \mathrm{~b}$ & 40 & 10541 & 24096 \\
\hline & $100000 \mathrm{~b}$ & 80 & 21083 & 48193 \\
\hline \multirow{3}{*}{$\begin{array}{l}\qquad(25,150) \\
\text { outside of sensor field } \\
\text { (Lifetime unit=round) }\end{array}$} & $10000 \mathrm{~b}$ & $\begin{array}{l}\text { Not enough } \\
\text { for one round }\end{array}$ & 66 & 95 \\
\hline & $50000 \mathrm{~b}$ & 3 & 331 & 479 \\
\hline & $100000 \mathrm{~b}$ & 6 & 662 & 958 \\
\hline
\end{tabular}

\subsection{Large-scale WSN with 1,000 sensor nodes}

To compare protocols in a large-scale WSN, we randomly deployed 1,000 sensor nodes in a $300 \times 300 \mathrm{~m}^{2}$ area. We put the base station at $(150,150)$ and $(150,500)$ respectively. 


\subsubsection{Chain structure comparison}

Figure 35 and Figure 36 show the structure of the greedy chain and the SA chain. The greedy chain shows many crosses, and some of these crosses are long-range. The SA chain has no crosses.

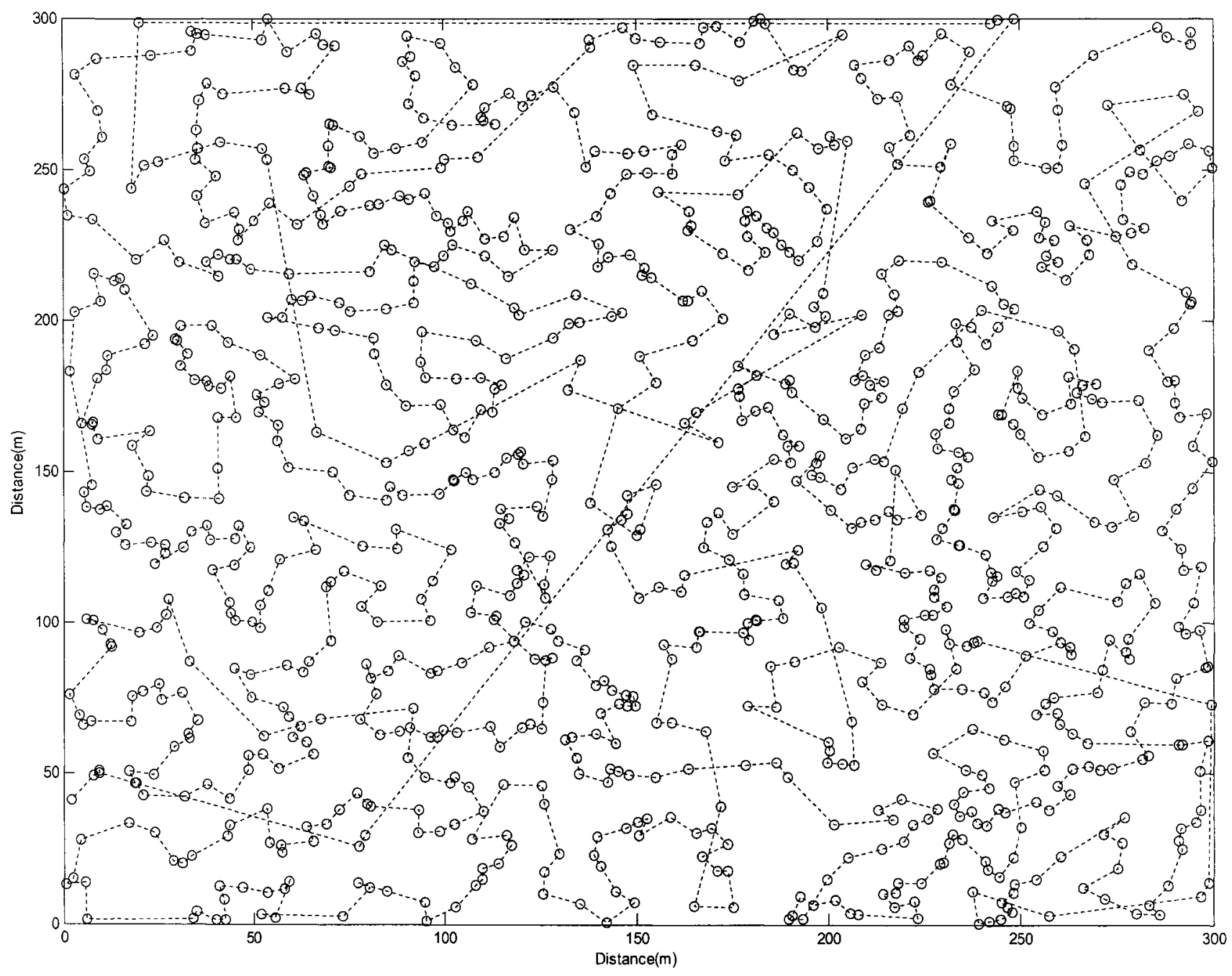

Figure 35: 1,000-node, Greedy chain 


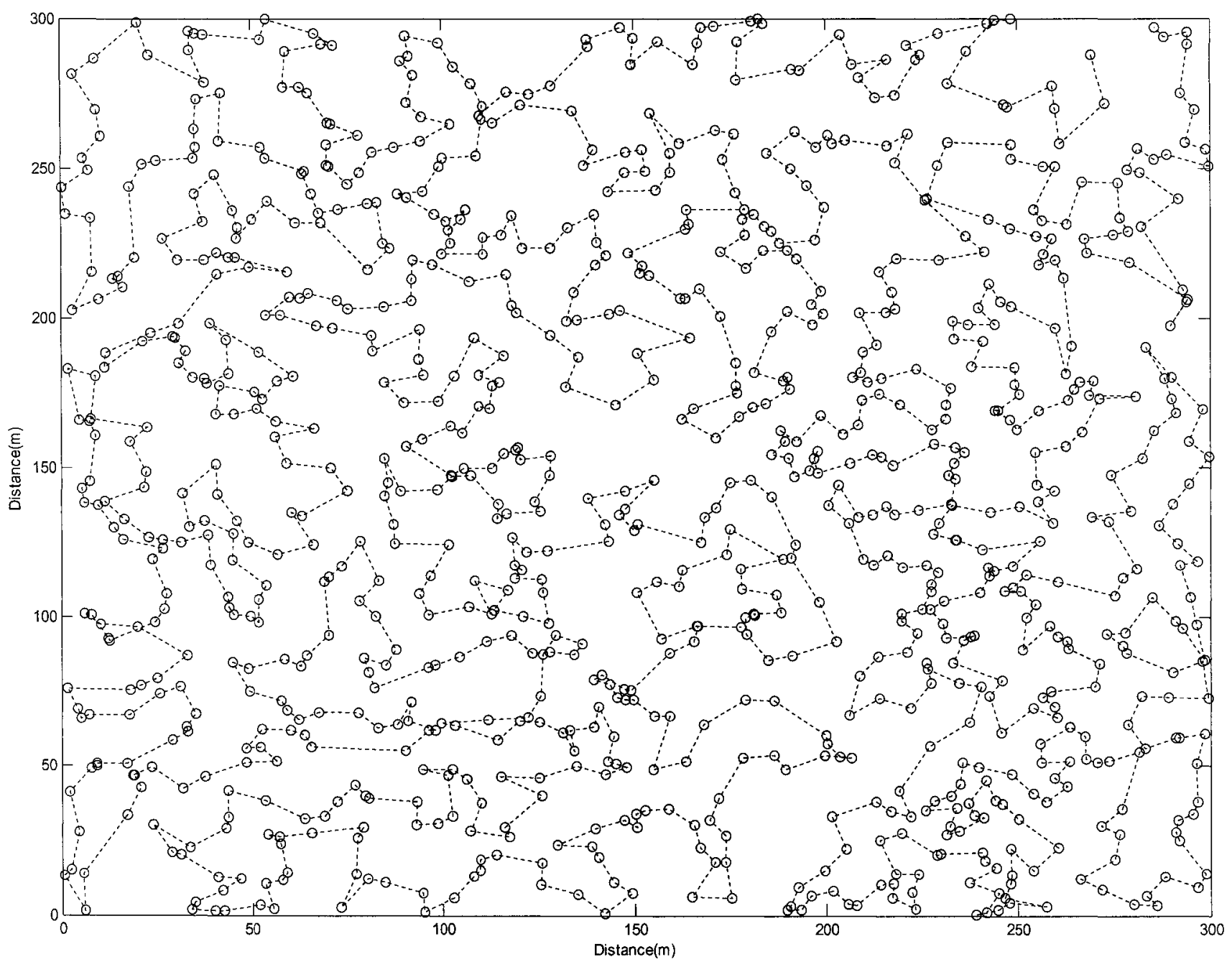

Figure 36: 1,000-node, SA chain

\subsubsection{Energy efficiency comparison}

We calculated the energy consumption over 1,000 data-gathering rounds. We also recorded the computational time of each algorithm. The result is shown in Table 7. 
Table 7: Energy efficiency and computation time comparison in a 1,000-node WSN

\begin{tabular}{|c|c|c|c|}
\hline $\begin{array}{c}\text { Base station } \\
\text { position }\end{array}$ & Direct & PEGASIS & SA chain \\
\hline $\begin{array}{c}(150,150) \\
\text { Inside of sensor field } \\
\text { (Energy unit=b) }\end{array}$ & 14862174644 & 15134139 & 123012.5 \\
\hline $\begin{array}{c}\text { Outside of sensor field } \\
\text { (Energy unit=b) }\end{array}$ & 143105813236 & 143319802 & 41221867 \\
\hline $\begin{array}{c}\text { Computation time } \\
\text { (Second) }\end{array}$ & 0 & 15.6 & 713.48 \\
\hline
\end{tabular}

Table 7 shows that the PEGASIS protocol consumes 123 times more energy than the SA chain when the base station is inside the sensor field, and 3.5 times when the base station is outside the sensor field. The direct communication protocol consumes 1,000 to 12,000 times more energy than the PEGASIS and SA chain protocols.

Figure 37 shows the comparison between the PEGASIS protocol and the SA chain protocol. The SA chain protocol consumed only $1 \%$ to $29 \%$ of the energy that the PEGASIS protocol did, while the SA chain protocol cost 698 seconds more time in the pre-setup phase. 


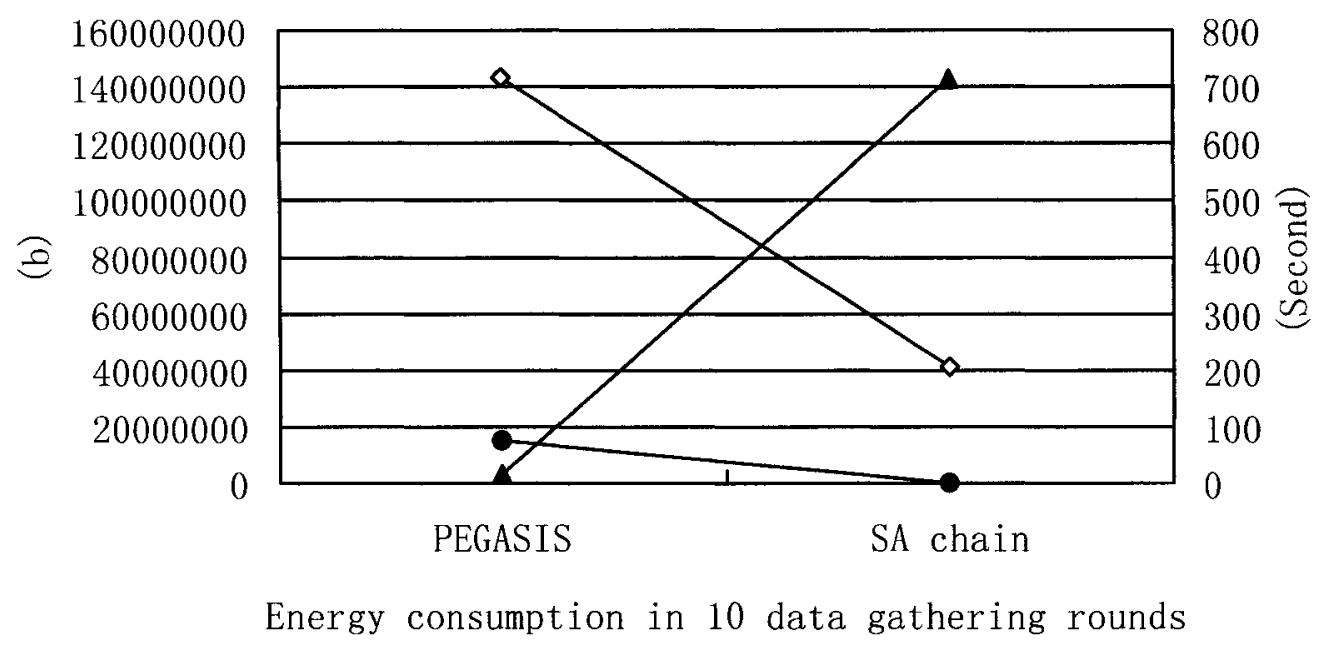

Inside sensor field $\diamond$ outside sensor field $\rightarrow$ Computation time

\section{Figure 37: Energy efficiency and computation time comparison in a 1,000-node}

WSN

\subsubsection{Lifetime comparison}

Given $1 \times 10^{5} \mathrm{~b}, 5 \times 10^{5} \mathrm{~b}$, and $1 \times 10^{6} \mathrm{~b}$ units of energy for each sensor node respectively, the average lifetime is shown in Table $\mathbf{8}$. When the base station is inside the sensor field, the lifetime of the SA chain protocol is 13 times longer than the PEGASIS protocol. When the base station is outside the sensor field, the lifetime of the SA chain protocol is 1.5 times longer than the PEGASIS protocol. The lifetime of the PEGASIS protocol is 3,303 times longer than the direct transmission protocol when the base station is inside the sensor field. When the base station is outside the sensor field, $10^{6} \mathrm{~b}$ energy is not enough for the farthest sensor node to transmit one packet directly to the base station. 
Table 8: Lifetime comparison in a 1,000-node WSN

\begin{tabular}{|c|c|c|c|c|}
\hline $\begin{array}{l}\text { Base station } \\
\text { position }\end{array}$ & $\begin{array}{c}\text { Initial } \\
\text { sensor node } \\
\text { energy }\end{array}$ & Direct & PEGASIS & SA chain \\
\hline \multirow{3}{*}{$\begin{array}{l}(150,150) \\
\text { inside of sensor field } \\
\text { (lifetime unit=round) }\end{array}$} & $10000 \mathrm{~b}$ & $\begin{array}{l}\text { Not enough } \\
\text { for one round }\end{array}$ & 660 & 8129 \\
\hline & $50000 b$ & $\begin{array}{l}\text { Not enough } \\
\text { for one round }\end{array}$ & 3303 & 24096 \\
\hline & $100000 \mathrm{~b}$ & 2 & 6607 & 81293 \\
\hline \multirow{3}{*}{$\begin{array}{l}\qquad(150,500 \\
\text { outside of sensor field } \\
\text { (lifetime unit=round) }\end{array}$} & $10000 \mathrm{~b}$ & $\begin{array}{l}\text { Not enough } \\
\text { for one round }\end{array}$ & 66 & 95 \\
\hline & $50000 \mathrm{~b}$ & $\begin{array}{l}\text { Not enough } \\
\text { for one round }\end{array}$ & 349 & 1213 \\
\hline & $100000 \mathrm{~b}$ & $\begin{array}{l}\text { Not enough } \\
\text { for one round }\end{array}$ & 662 & 958 \\
\hline
\end{tabular}




\section{CONCLUSIONS AND FUTURE RESEARCH}

This chapter contains a summary of the advantages and the limitation of the SA chain protocol and indicates new research areas.

\subsection{Conclusions}

From the simulation results in Chapter 5, the following conclusions can be drawn.

First, the SA chain protocol divides the work between the sensor nodes and the base station; it simplifies the sensor node computation and lowers its communication workload. It also can build the routing table for sensor nodes from global information. The PEGASIS protocol builds the routing table from local information.

The SA chain protocol can build an approximately optimal cost data communication route for a randomly deployed WSN. It can conveniently define or change the cost of each link when required.

The SA chain protocol provides an energy-efficient solution for applications. By comparing the simulation results, we can conclude that with respect to energy efficiency, the SA chain protocol outperforms the PEGASIS protocol. 
The SA chain protocol can provide a longer lifetime. The simulation results also show that the lifetime of the SA chain protocol is 1.5 times to 15 times longer than the PEGASIS protocol.

In summary, the conclusion is that the SA chain protocol can provide an energy-efficient data gathering and communication solution for wireless sensor networks.

\subsection{Limitations}

The limitation of this protocol is assuming sensor nodes perform a data fusion function, which is applied widely in WSNs. However, in some applications, WSNs gather large quantity information, such as image information. In these applications, the data fusion function is difficult to compress data. It will cause that data packages transmitted on the SA chain become larger after pass a sensor node. Thus, sensor nodes that are closer to the chain leader consume more energy. In some special situations, the clustering protocols, such as LEACH, would have better performance than the chain based protocols, such as PEGASIS and SA chain protocols. For these large quantity information gathering applications, the routing protocol should be redesigned.

\subsection{Future work}

Future work can be carried out on dynamic changes in WSNs, which include the death of sensor nodes and mobile sensor nodes. 
Another interesting area in which further research could be conducted is the particular WSN setting. For example, more constraints, such as limited transmission range or a different initial sensor node energy level, can be taken into consideration. 


\section{REFERENCE}

[1] A. Mainwaring, J. Polastre, R. Szewczyk, D. E. Culler, and J. Anderson, "Wireless sensor networks for habitat monitoring," Proc. ACM International Workshop on Wireless Sensor Networks and Applications, 2002, pp.88-97

[2] D. Li, K.D. Wong, Y.H. Hu and A.M. Sayeed, "Detection, classification and tracking of targets,” IEEE Signal Processing Magazine, Vol. 19, No.2, 2002, pp.17-29

[3] M. Ridley, E. Nettleton, S. Sukkarieh and H. Durrant-Whyte, "Tracking in decentralised air-ground sensing networks," Proc. the $5^{\text {th }}$ International Conference on Information Fusion, 2002, pp. 616-623

[4] J. Nemeroff, L. Garcia, D. Hampel and S. DiPierro, "Application of sensor network communications," Proc. IEEE Military Communications Conference MILCOM, 2001, pp.336-341

[5] D.C. Steere, A. Baptista, D. McNamee, C. Pu and J. Walpole, "Research challenges in environmental observation and forecasting systems," Proc. the $6^{\text {th }}$ Annual International Conference on Mobile Computing and Networking, 2000, pp.292-299

[6] http://robotics.eecs.berkeley.edu/ pister/SmartDust/ (available until May, 2006)

[7] http://www.eecs.harvard.edu/ mdw/proj/vitaldust/ (available until May, 2006)

[8] Y. Fujino and M. Abe, "Structural Health Monitoring in Civil Infrastructures and Research on SHM of Bridges at the University of Tokyo," Proc. of the Third World Conference on Structural Control, Vol.1, 2002, pp. 125-140 
[9] http://www.pnsn.org/INFO_GENERAL/INFOSHEET/welcome.html, (available until April, 2006)

[10] N. Xu, S. Rangwala, K. Chintalapudi, D. Ganesan, A. Broad, R. Govindan and D. Estrin, "A wireless sensor network for structural monitoring," Proc. the $2^{\text {nd }}$ International Conference on Embedded Networked Sensor Systems, 2004, pp.13-24

[11] I. F. Akyildiz, W. Su, Y. Sankarasubramaniam and E. Cayirci, "A survey on sensor networks," IEEE Communications Magazine, Vol. 40, No. 8, 2002, pp.102-114

[12] K. Sourabi, J. Gao, V. Ailawadni and G. J. Pottie, "Protocols for self-organization of a wireless sensor network," IEEE Personal Communications, Vol. 7, No. 5, 2000, pp.16-27

[13] Rappaport, S. Theodore, Wireless communications: principles and practice, Upper Saddle River, N.J, Prentice Hall, 1996.

[14] S. H. Cho and A. P. Chandrakasan, "Energy efficient protocols for low duty cycle wireless microsensor networks," IEEE International Conference on Acoustics, Speech and Signal Processing - Proceedings, 2001, pp.2041-2044

[15] The Pacific Northwest Seismograph Network; http://www.pnsn.org/INFO_GENERAL/INFOSHEET/welcome.html (available until May, 2006)

[16] R. Kalidindi, L. Ray, R. Kannan, and S.S. Iyengar, "Distributed energy-aware MAC protocol for wireless sensor networks," International Conference on Wireless Networks, 2003, pp.282-286 
[17] K. Sohrabi and G.J. Pottie, "Performance of a novel self-organization protocol for wireless ad hoc sensor networks," Proc. the IEEE 50 $0^{\text {th }}$ Vehicular Technology Conference, 1999, pp.1222-1226

[18] V. Rajendran, K. Obraczka and J.J. Garcia-Luna-Aceves, "Energy-efficient, collision-free medium access control for wireless sensor networks," Proc. the $1^{\text {st }}$ International Conference on Embedded Networked Sensor Systems, 2003, pp. $181-192$

[19] W. Ye, J. Heidemann, and D. Estrin, “Energy-efficient MAC protocol for wireless sensor networks," Proc. the $21^{\text {st }}$ International Annual Joint Conference of the IEEE Computer and Communications Societies, 2002, pp.1567-1576

[20] T. van Dam and K. Langendoen, "An adaptive energy-efficient MAC protocol for wireless sensor networks," Proc. the $1^{\text {st }}$ International Conference on Embedded Networked Sensor Systems, 2003, pp.171-180

[21] F. Tobagi and L. Kleinrock, "Packet switching in radio channels: Part II - the hidden terminal problem in carrier sense multiple access and the busy-tone solution," IEEE Trans. Communications, Vol.23, No.2, 1975, pp.1417-1433

[22] LAN MAN Standards Committee of the IEEE Computer Society, Wireless LAN medium access control (MAC) and physical layer (PHY) specification, IEEE, New York, NY, USA, IEEE Std 802.11,1999 edition, 1999

[23] http://www.inetdaemon.com/tutorials/internet/ip/routing/flat_vs_hierarchical.shtml (available until May, 2006) 
[24] S. Hedetniemi and A. Liestman, "A survey of gossiping and broadcasting," Communication Networks, Vol.18, No.4, 1988, pp.319-349

[25] J. Kulik, W. R. Heinzelman and H. Balakrishnan, "Negotiation-based protocols for disseminating information in wireless sensor networks," Wireless Networks, Vol.8, No.2-3, 2002, pp.169-185

[26] W. R. Heinzelman, A. Chandrakasan, and H. Balakrishnan, "Energy efficient communication protocol for wireless micro-sensor networks," Proc. IEEE International Conference on System Sciences, 2000, pp.4-7

[27] S. Lindsey and C. Raghavendra, "PEGASIS: power-efficient gathering in sensor information systems," IEEE Aerospace Conference, 2002, pp.1125-1130

[28] S. Lindsey, C. Raghavendra and K.M. Sivalingam, "Data gathering algorithms in sensor networks using energy metrics," IEEE Trans. Parallel and Distributed Systems, Vol.13, No.9, 2002, pp.924-935

[29] Rappaport, S. Theodore, Wireless communications: principles and practice, Upper Saddle River, N.J, Prentice Hall PTR, 2002

[30] G. B. Dantzig, R. Fulkerson, and S. M. Johnson, "Solution of a large-scale traveling salesman problem," Operations Research, 1954, pp 393-410

[31] N. L. Biggs, E. K. LLoyd, and R. J. Wilson, Clarendon, Graph Theory, Press, Oxford, 1976

[32] http://homepages.cwi.nl/ lex/files/histco.ps (available until May, 2006)

[33] http://www.tsp.gatech.edu/history/index.html (available until May, 2006)

[34] http://en.wikipedia.org/wiki/Hamiltonian path (available until May, 2006) 
[35] Hamilton, W. Rowan, "Account of the icosian calculus," Proc. the Royal Irish Academy, 1858, pp.6

[36] N. Metropolis, A. Rosenbluth, M. Rosenbluth, A. H. Teller, and E. Teller, "Equation of state calculations by fast computing machines," Journal of Chemical Physics, vol. 21, 1953, pp.1087-1092

[37] Kirkpatrick S, Gelatt CD, Vecchi MP, "Optimization by simulated annealing," Science, Vol.220, No.4598, 1983, pp.671-80.

[38] http://members.aol.com/btluke/simanf2.htm (available until May, 2006)

[39] http://en.wikipedia.org/wiki/Simulated_annealing (available until May, 2006) 